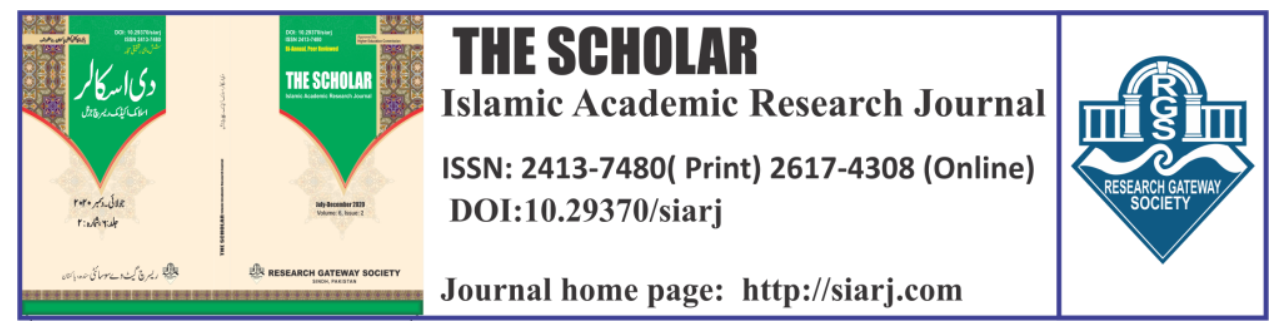

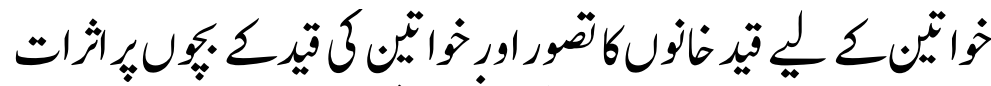

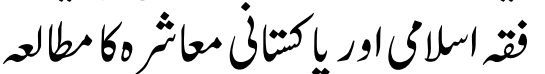

\title{
THE CONCEPT OF PRISONS FOR WOMEN AND THE IMPACT OF IMPRISONMENT ON CHILDREN - A STUDY IN THE CONTEXT OF ISLAMIC JURISPRUDENCE AND PAKISTANI SOCIETY
}

\section{Sajida Hanif}

PhD Scholar, Department of Islamic Studies

Department, College for Women University,

Lahore, Pakistan

Email: drsajidahanif@gmail.com

ORCID ID:

\section{Zahida Shabnam}

Associate Professor, Department, Islamic Studies Department, Lahore College for Women University, Lahore, Pakistan Email: zahida.shabnum@lcwu.edu.pk

\section{ORCID ID:}

http://orcid.org/0000-0003-0035-6106

\section{http://orcid.org/0000-0003-4904-3872}

To cite this article:

Hanif, Sajida, and Zahida Shabnam. "URDU-THE CONCEPT OF PRISONS FOR WOMEN AND THE IMPACT OF IMPRISONMENT ON CHILDREN - A STUDY IN THE CONTEXT OF ISLAMIC JURISPRUDENCE AND PAKISTANI SOCIETY." The Scholar-Islamic Academic Research Journal 7, No. 1 (February 18, 2021). : 1-22

To link to this article: https://doi.org/10.29370/siarj/issue12urduar1

Journal

Publisher

DOI:

URL:

License:

Journal homepage

Published online:
The Scholar Islamic Academic Research Journal

Vol. 7, No. 1 || January -June 2021 || P. 1-22

Research Gateway Society

10.29370/siarj/issue12urduar1

https://doi.org/10.29370/siarj/ issue12urduar1

Copyright c 2017 NC-SA 4.0

www.siarj.com

2021-02-18

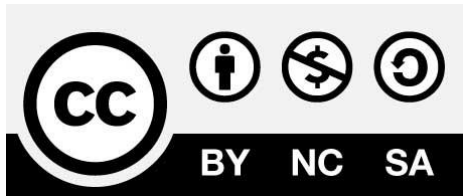

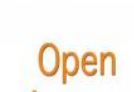

Access
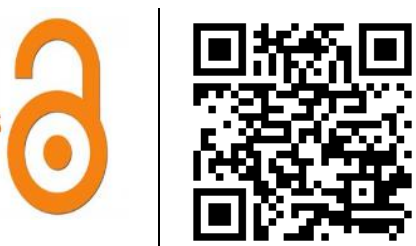


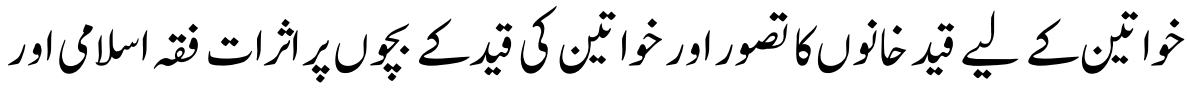

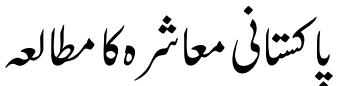 \\ THE CONCEPT OF PRISONS FOR WOMEN AND THE IMPACT OF IMPRISONMENT ON CHILDREN - A STUDY IN THE CONTEXT OF ISLAMIC JURISPRUDENCE AND PAKISTANI SOCIETY
}

\begin{abstract}
Sajida Hanif, Zahida Shabnam

\section{ABSTRACT:}

To save the mutual relationships of humans from clash and in equilibrium and in order to curb crimes, Allah has enforced boundaries (Hudod) and penalties. One from of penalizing is "imprisonment". According to the prevailing system the imprisonment of women duly disturbs their domestic affairs. Their children also get dual effects both social and psychological. As per Pakistan's Law, the mothers in prison can keep their children upto 6 years. Although the children in prison not only loose the lap of their mother but the environment of prison, malnutrition food, scarce space, abusive language and slang terms of other women do create a negative impact over the minds of children. Mental and physical nourishment gets affected. On the other hand, children of the imprisoned women, who are away from their mothers, get deprived of their affection. Society has a critical view about them. Therefore, in order to mitigate these effects, an appropriate environment and facilities of education and development must be provided. It is better that the (prisons) either be released on bail or detained in their homes. Moreover, family quarters could be built in the Jails so children might experience home like environment.
\end{abstract}


KEYWORDS: Imprisonment, Women Prisoner, Children, Women

Rights, Jail Environment, Islamic Law

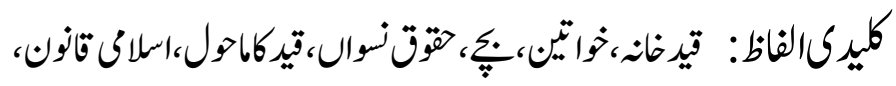

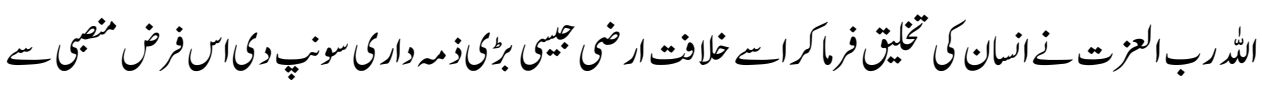

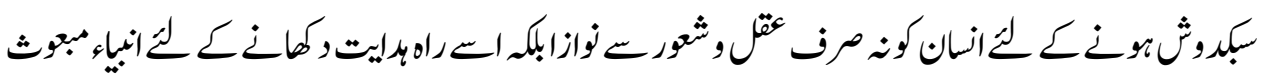

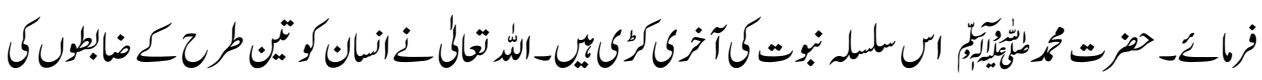

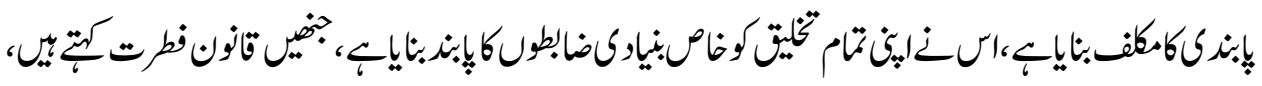

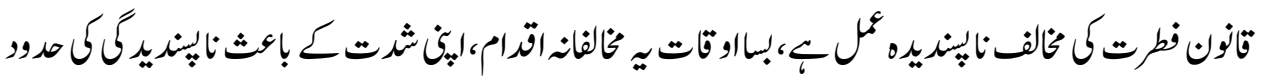

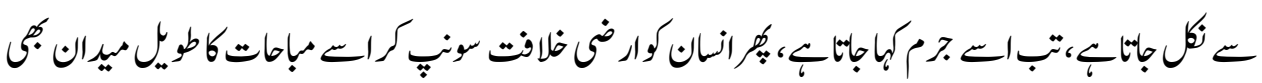

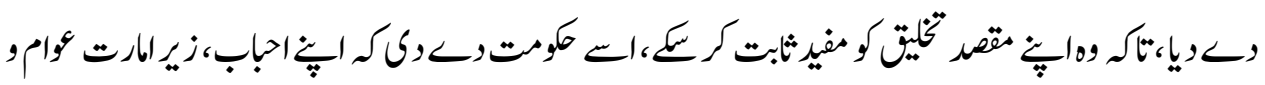

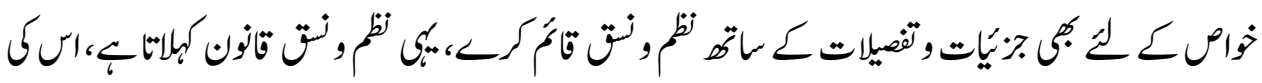

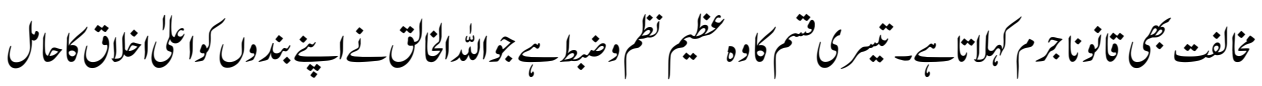

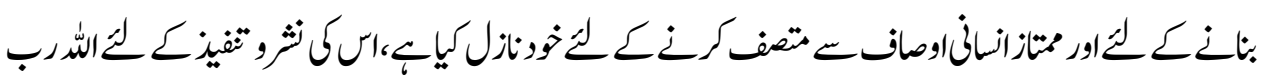

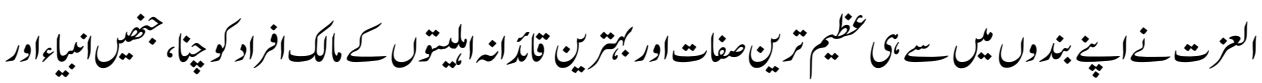

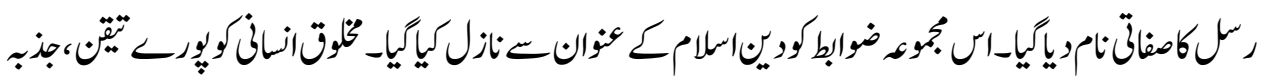

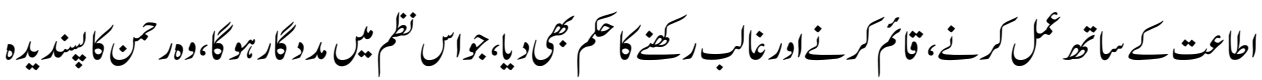

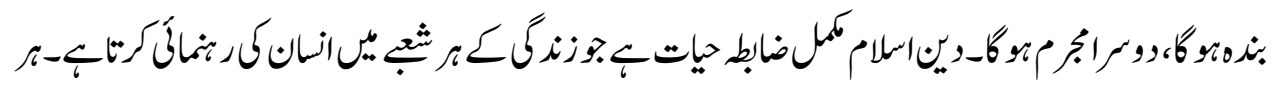

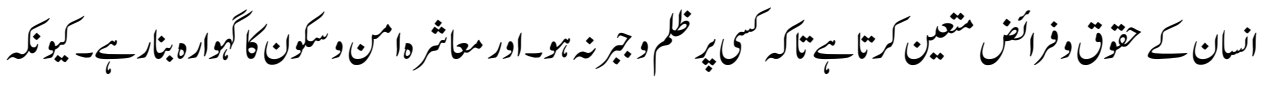

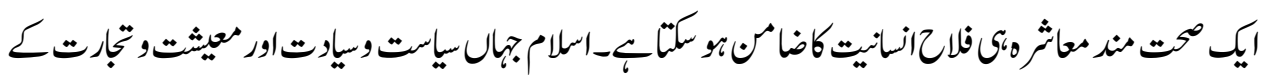

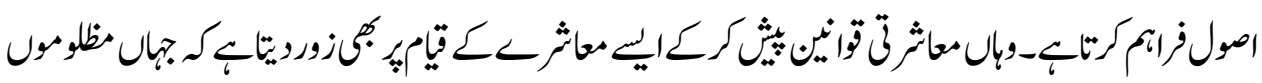

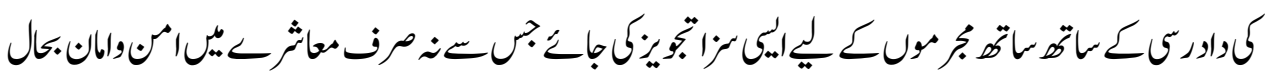

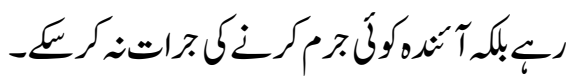

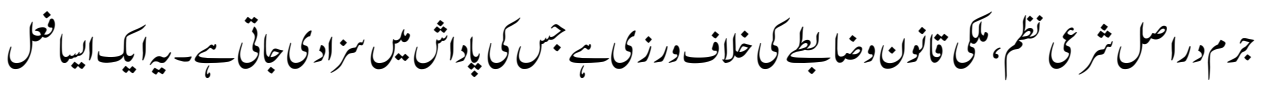

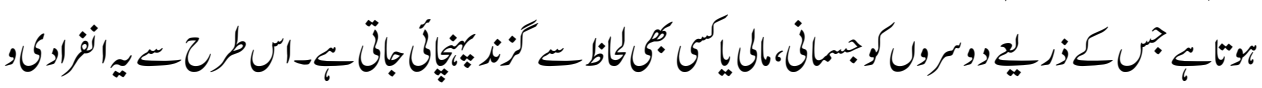




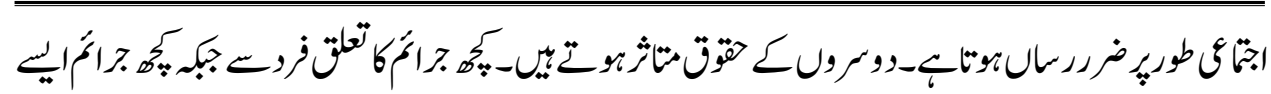

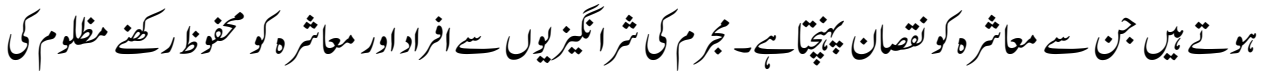

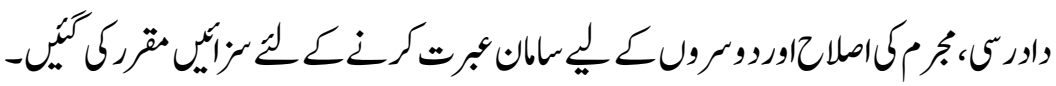

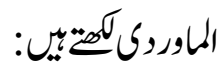

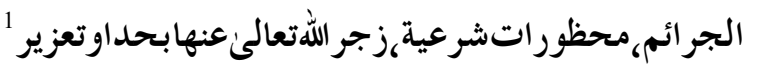

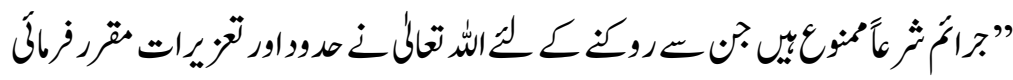
".

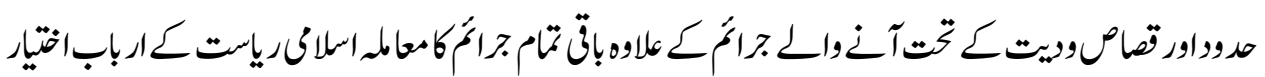

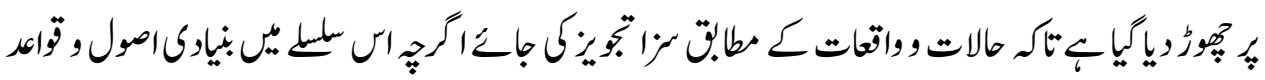

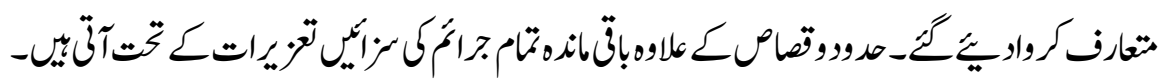

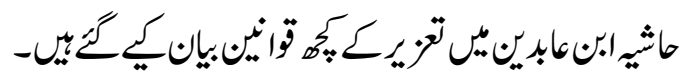

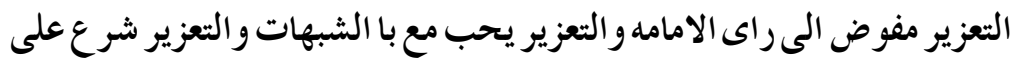

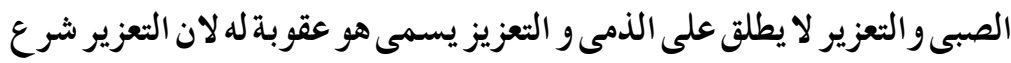

$$
\text { للتطهير }
$$

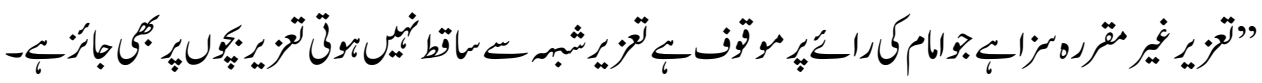

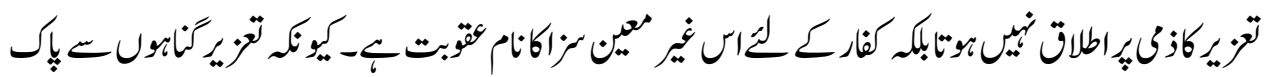

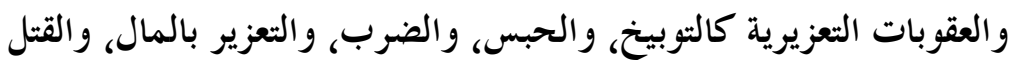

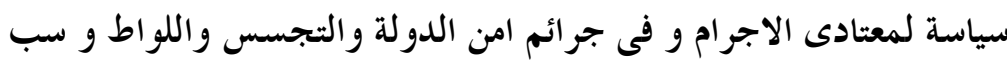

\footnotetext{
${ }^{1}$ Abū al-Hasan 'Alī Ibn Muhammad Ibn Habīb Al-Māwardī, Al-Ahkam As-Sultaniyyah (Beirut: Darul Kutaab Al-Arabi, 1999), 361.

${ }^{2}$ Muhammad Ameen Ibn Abidin, Radd Al-Muhtār 'ala al-Durr alMukhtār Sharh Tanwīr al-Absār, vol. 6 (Beirut: Darul Kutub al-Ilmiyyah, n.d.), 103.
} 


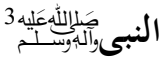

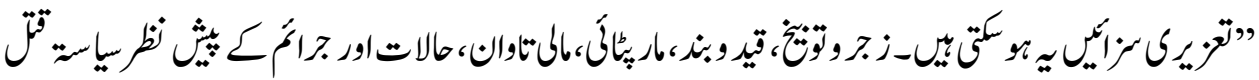

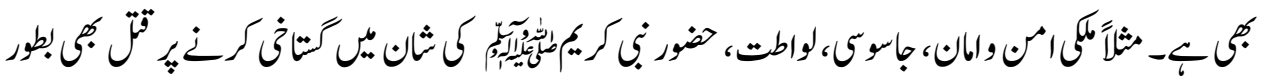

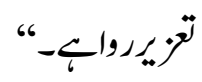

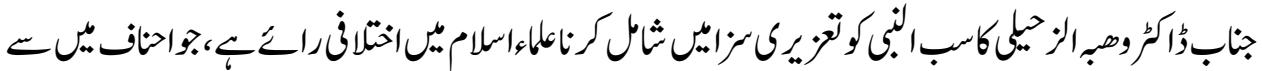

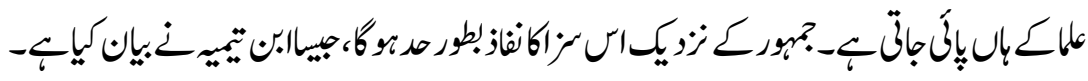

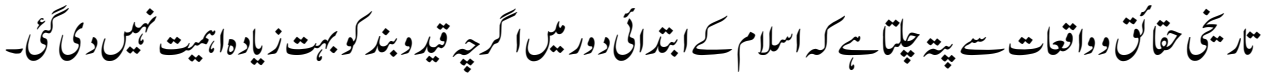

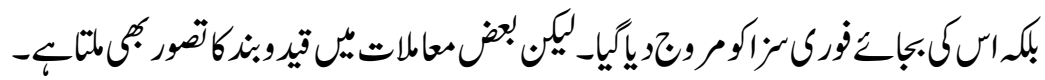

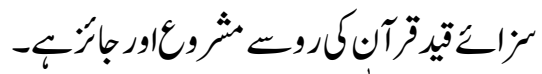

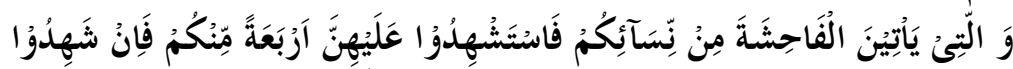

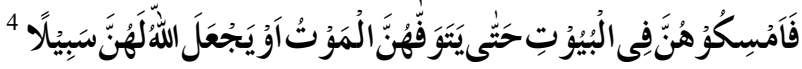

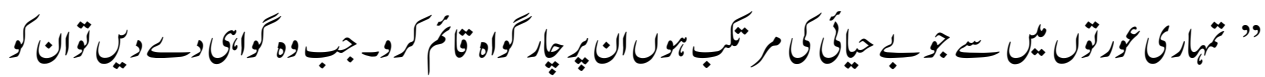

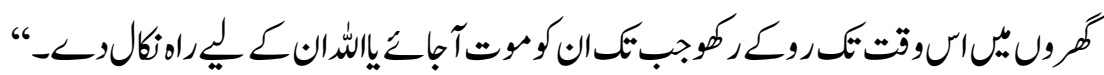

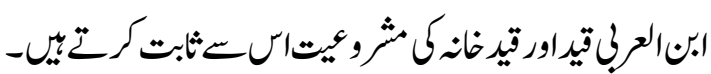

امساكهن فى البيوت وحبسهن فيها فى صدر الاسلامقبل ان تكثر الجناة، فلما كثر الجناةو خشىقوتهم اتخذلهمسجن 5

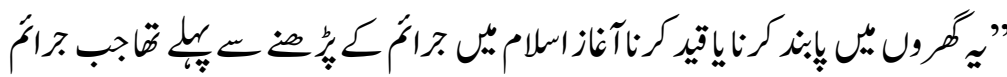

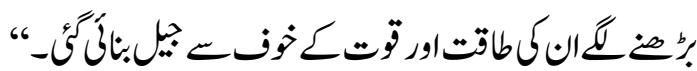

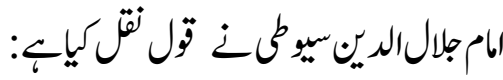
عن سعيد بن جبير (فامسكوهن) يعنى احبسوهن (فى البيوت) يعنى فى السجونـ

${ }^{3}$ Wahbah Zuhayli, Fiqh Al-Islami Wa-Adilatuhu, vol. 7 (Damascus: Darul Fikr, 1997), 5301.

${ }^{4}$ Al-Quran, 4:15.

${ }^{5}$ Abū Bakr Muhammad ibn Abdallāh Ibn al-Arabi, Ahkam Al-Quran, vol. 1 (Cairo: Maktabah-At-Taufiqiyyah, n.d.), 449. 


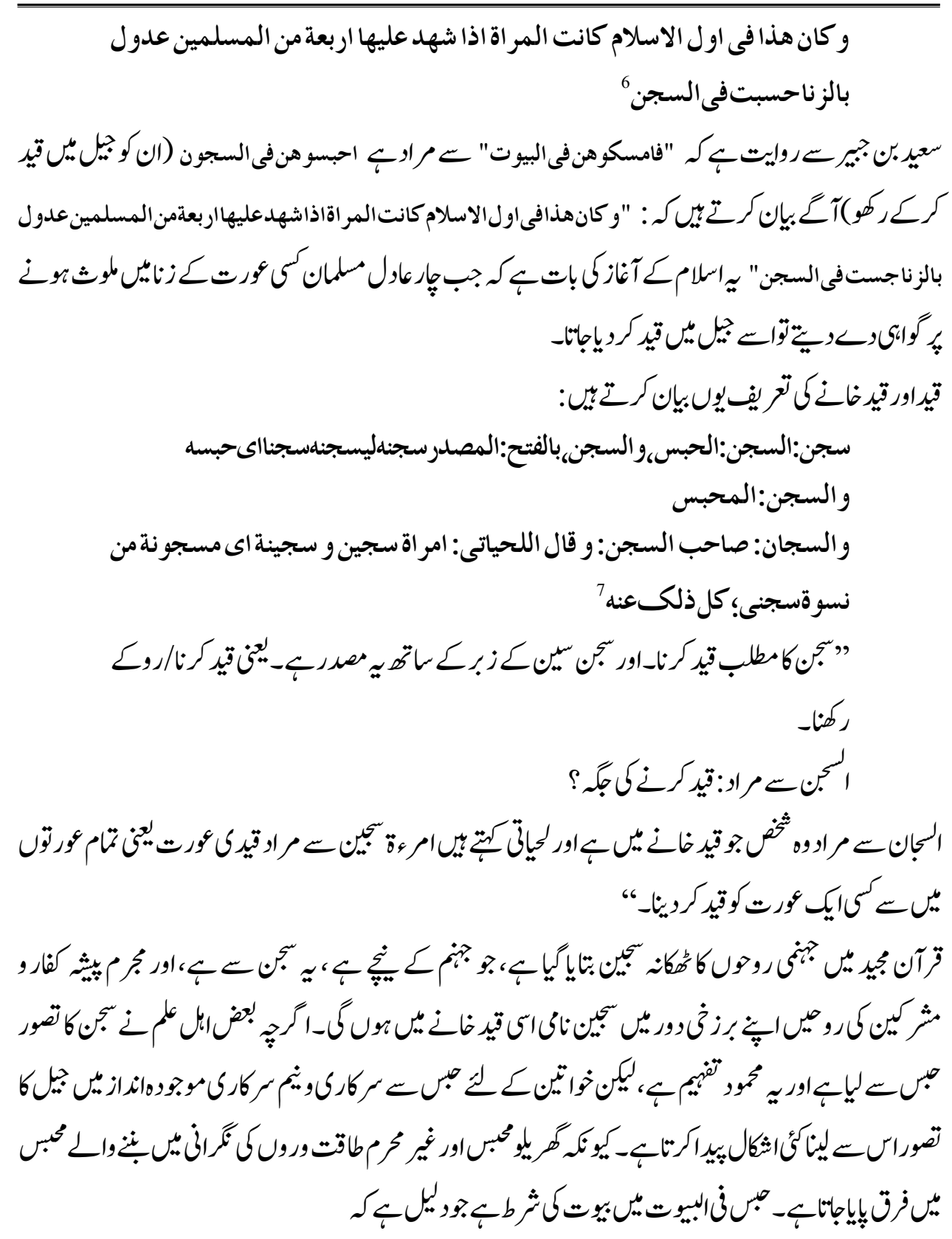

${ }^{6}$ Jalal al-Din Al-Suyuti, Al-Durr Al-Manthur Fi Tafsir Bil-Ma'thur, vol. 2 (Lebanon: Dār Ihỵā al-Turāth al-Arabī, 2000), 427.

7 Muhammad ibn Mukarram ibn Alī ibn Ahmad Ibn Manzūr, Lisan AlArab, vol. 13 (Beirut: Dar Sader, 1994), 203. 


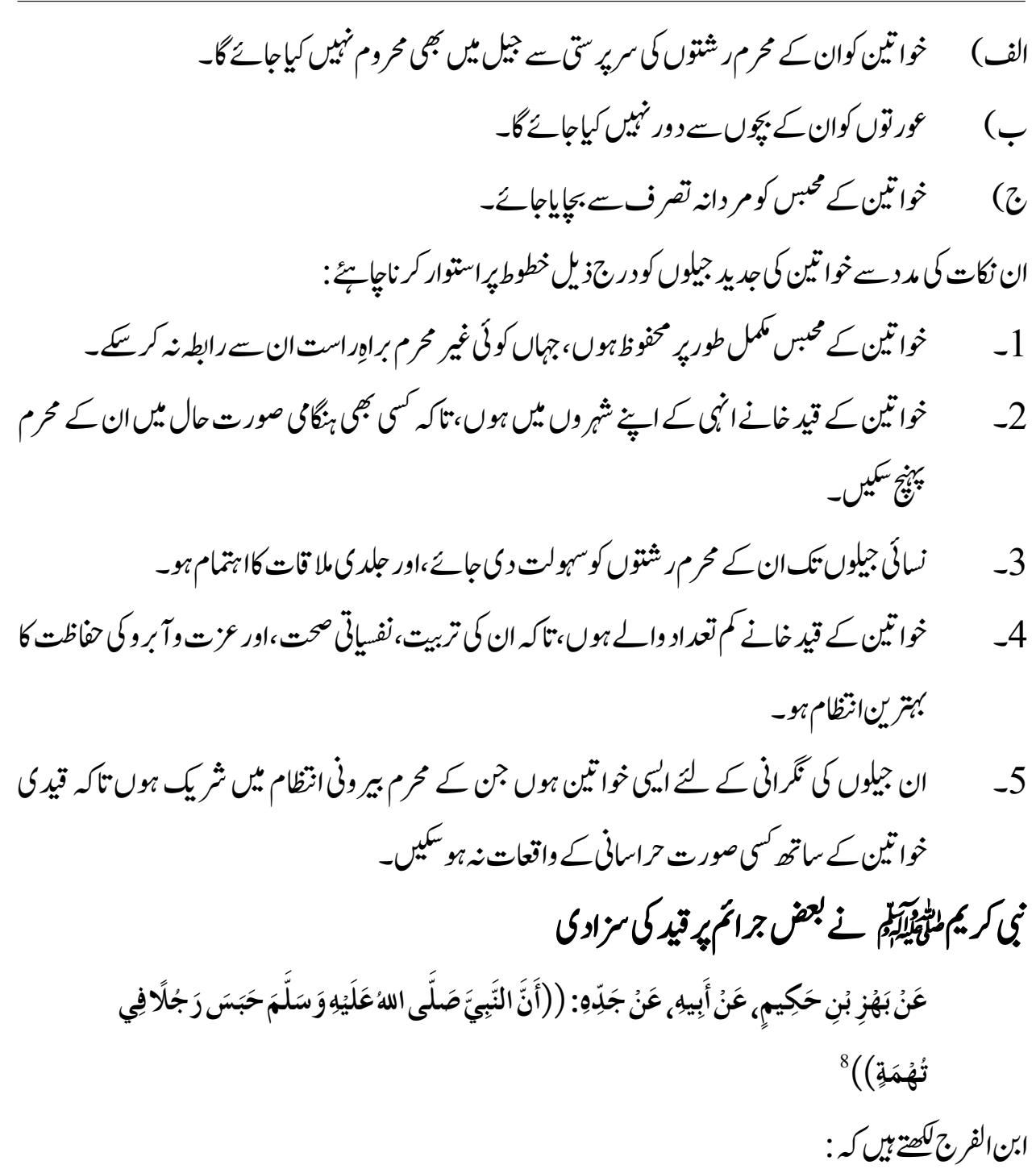

${ }^{8}$ Abū Dā’ūd Sulaymān ibn al-Ash'ath ibn Ishāa Al-Sijistān̄̄, Sunan Abū Dāwūd (Beirut: Al-Maktaba al Asriah, n.d.), Hadith: 3630. 


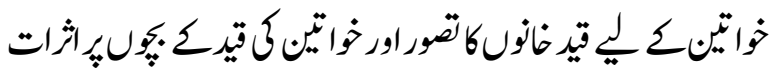

$$
\begin{aligned}
& \text { وثبت عن عمر بن الخطاب رضى الله عنه انه كان له سجن، انه سجن الحطيئة على }
\end{aligned}
$$

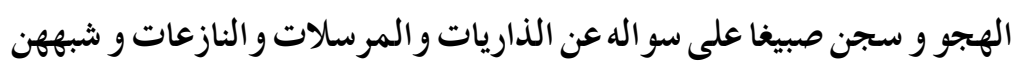

$$
\begin{aligned}
& \text { وامر الناس بالتفقه } 9
\end{aligned}
$$

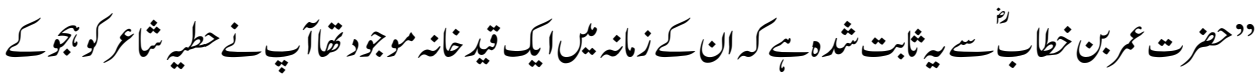

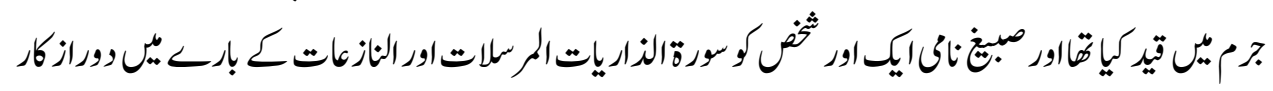

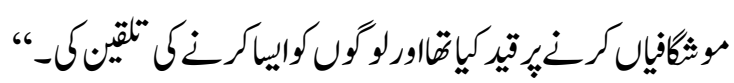

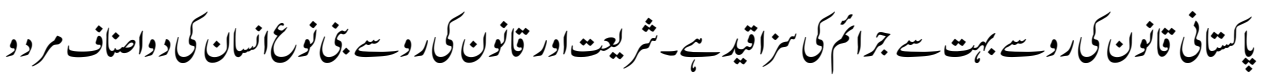

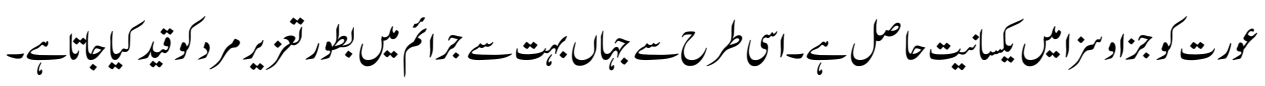

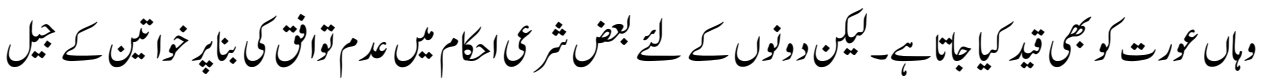

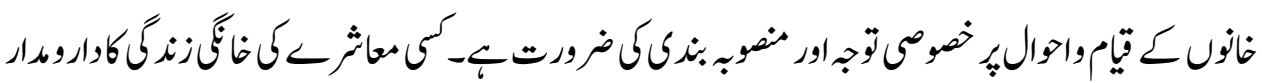

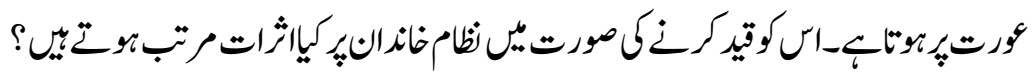

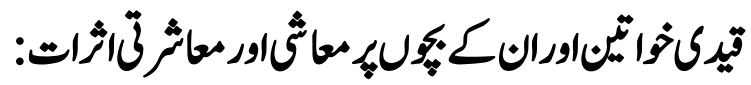

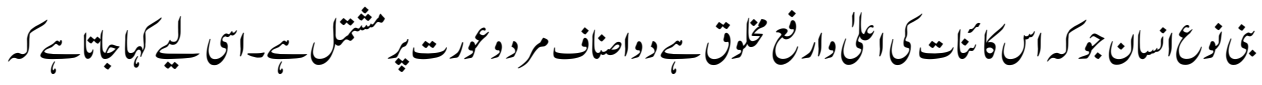

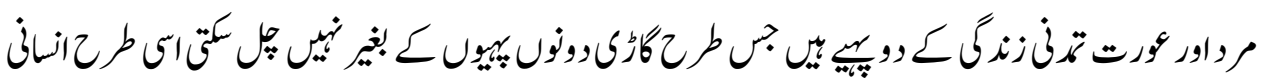

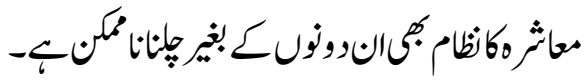
ارشاد بارى تعالئ هـ:

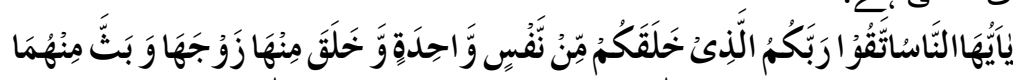

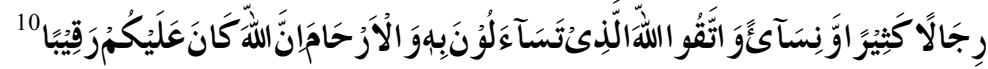

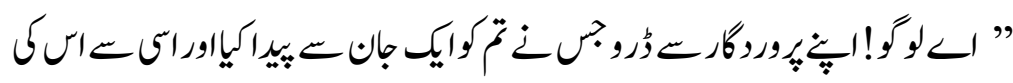

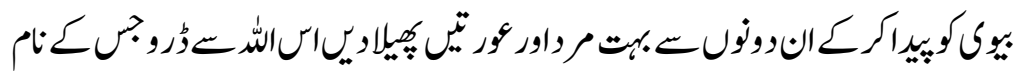

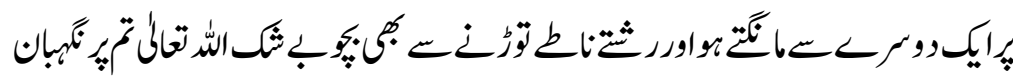

${ }^{9}$ Muhammad ibn Faraj Ibn al-Ṭallā, Aqdiyat Rasūl Allāh S.A.W.W (Beirut: Darul Kutaab Al-Arabi, 2005).

${ }^{10}$ Al-Quran, 4:1. 


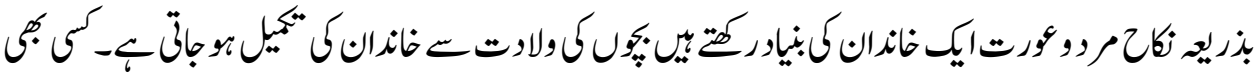

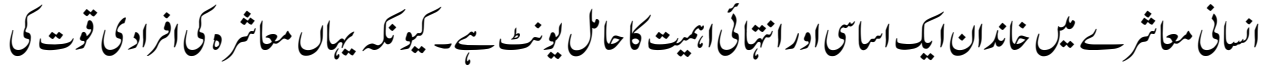

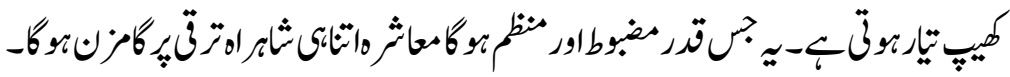

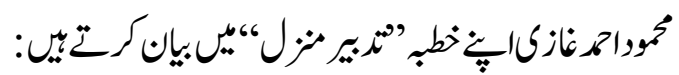

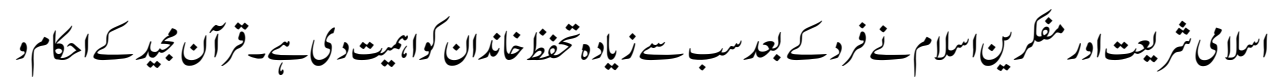

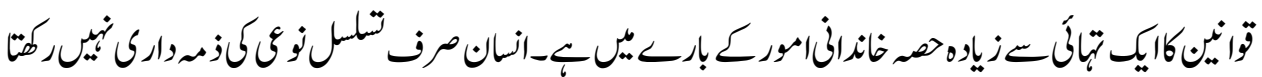

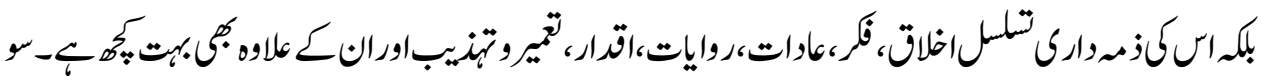

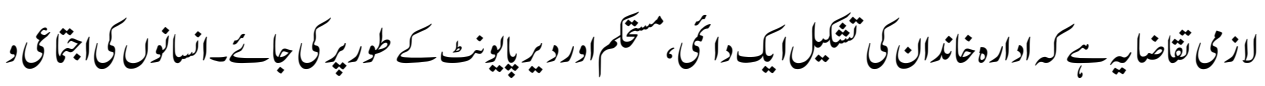

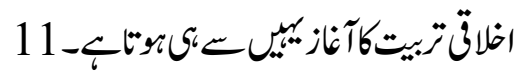

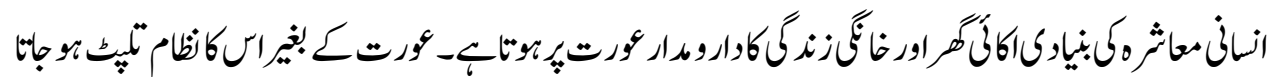

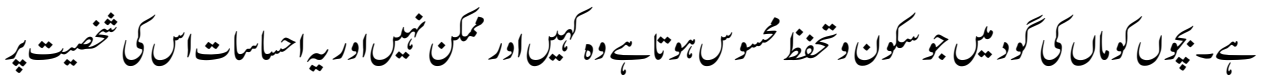

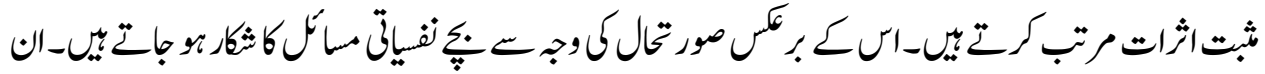

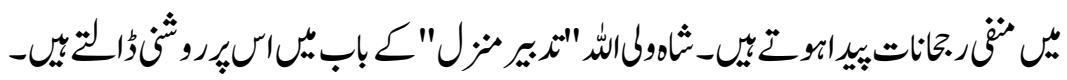

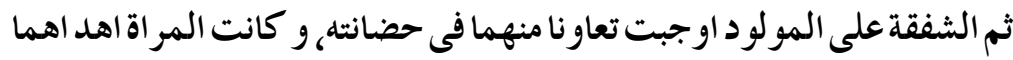
للحضانةبالطبع، انيكون تمرين الاو لادعلى ماينفعهم فطرة

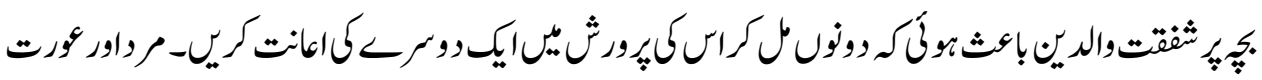

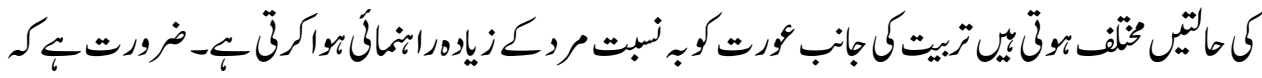

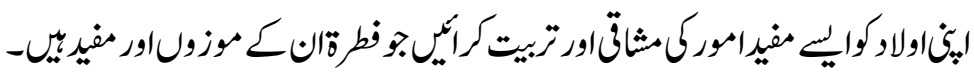

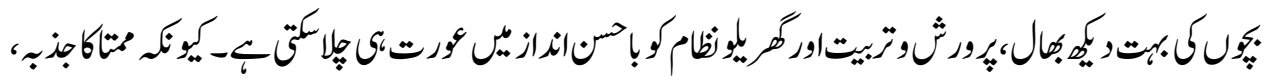

${ }^{11}$ Dr. Mehmood Ahmad Ghazi, Mahazrat e Shariat (Lahore: Al Faisal Nashran, 2009), 236-38.

${ }^{12}$ Shāh Walīullāh Dehlawī, Hujjatullah-Il-Baligha (Beirut: Darul Marifa, 2004), 97-99. 


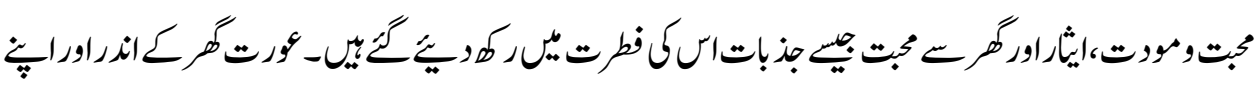

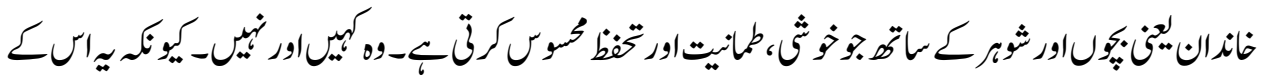

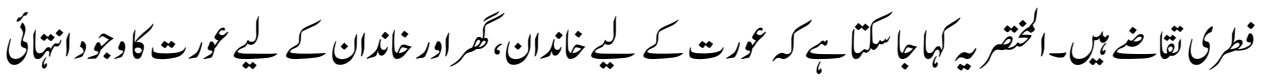

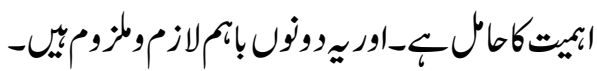

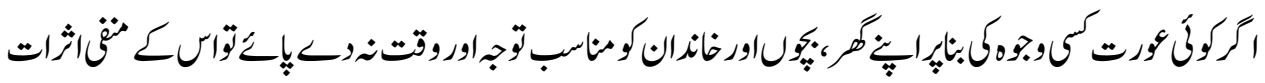

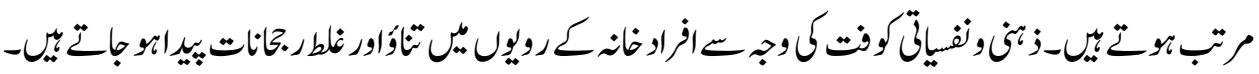

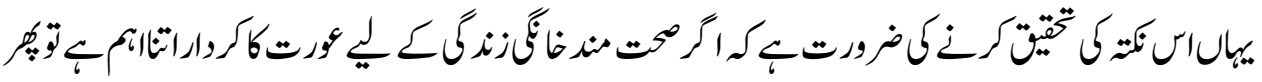
كم.

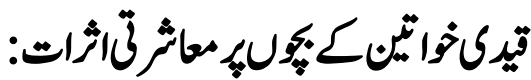

جزماتير

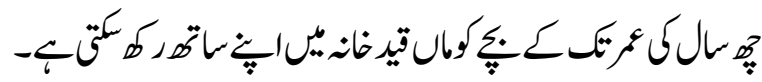

"Women prisoners shall be allowed to keep their children with them in prison till they attain the age of three years"13

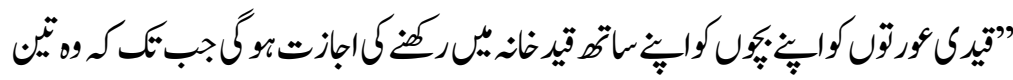

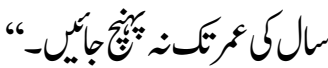

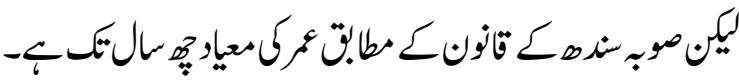
"In rule 326, for the words "three years" the words "six years" shall be substituted". ${ }^{14}$

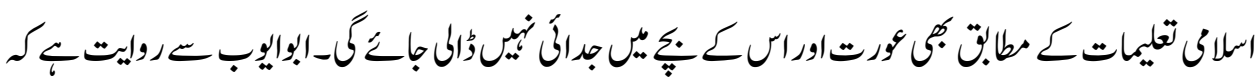

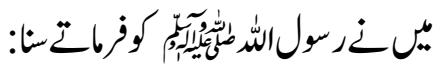

13 “Pakistan Prison Rules 1978," n.d., R: 326.

14 “Added by Sindh Province Notif. No. S.O. (Prs-II),” May 13, 1996. 


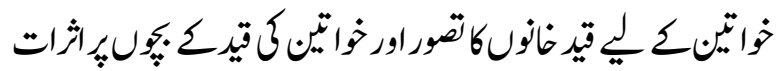

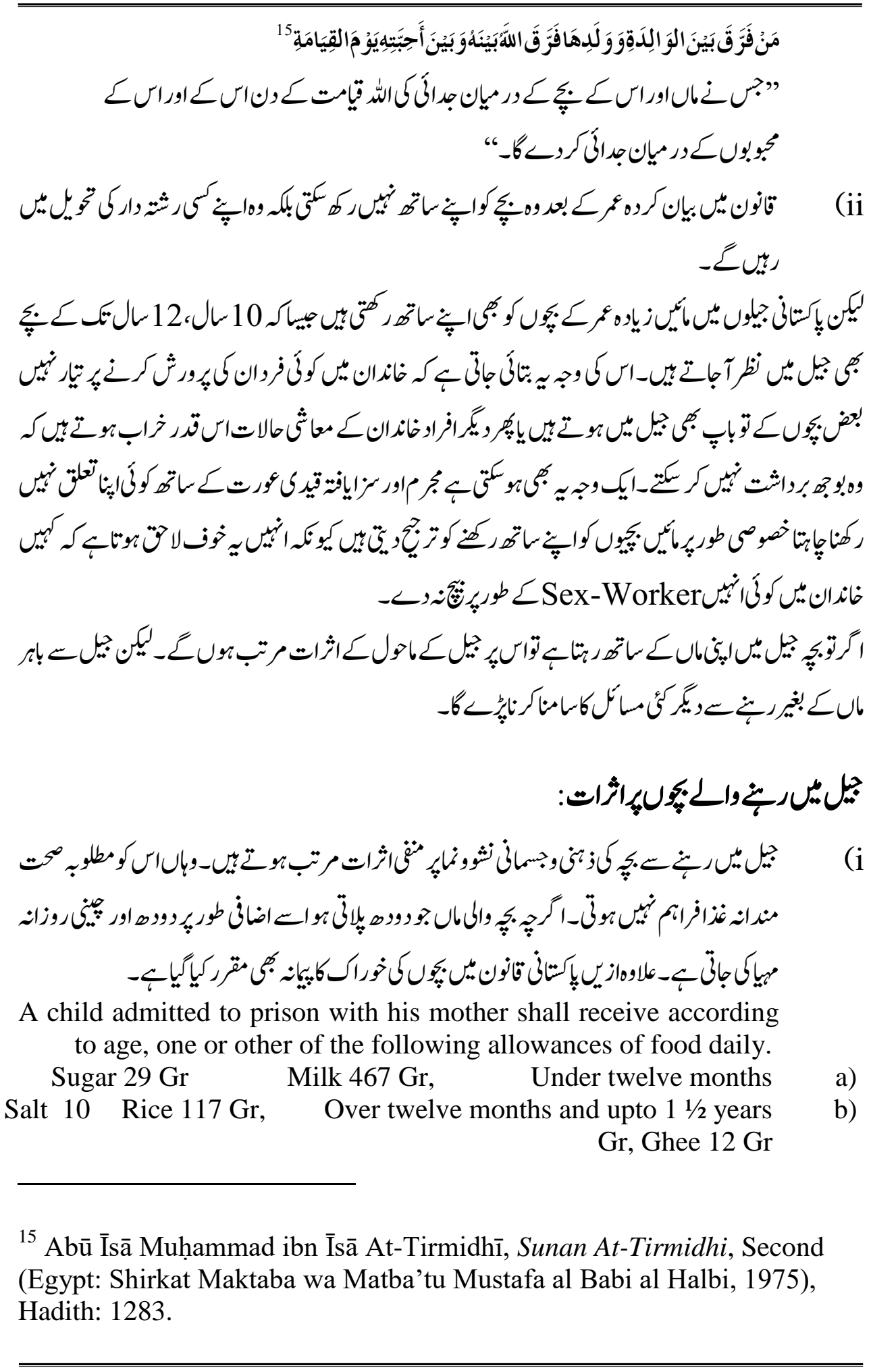


The Scholar Islamic Academic Research Journal

Vol. 7, No. 1 || January-June 2021 || P. 1-22

https://doi.org/10.29370/siarj/issue12urduar1

Extras when necessary shall be given as the medical officer directs.

$117 \mathrm{Gr}$ fresh fruit thrice weekly shall be issued to all children above the age of one year. ${ }^{16}$

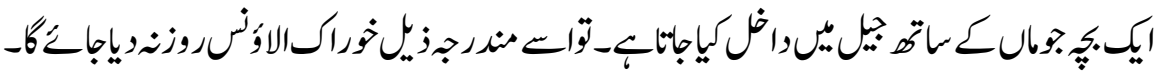

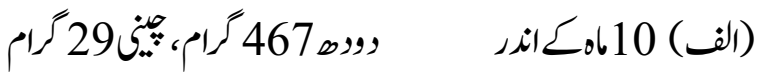

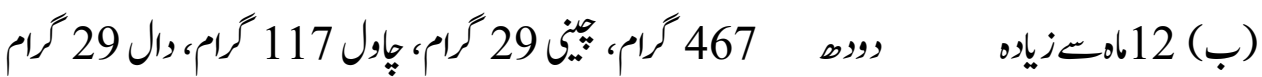

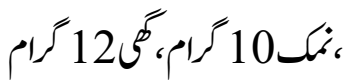

$$
\begin{aligned}
& \text { ） （ii } \\
& \text { ） （iii }
\end{aligned}
$$

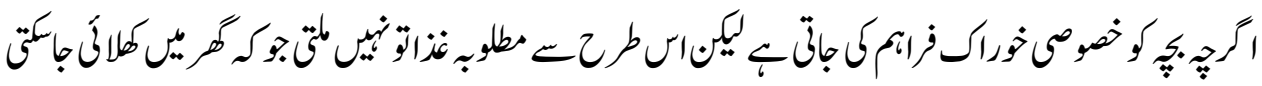

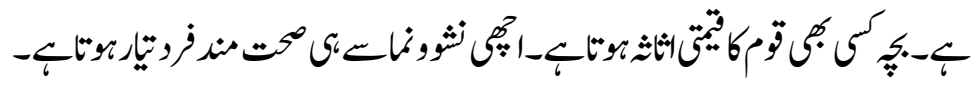

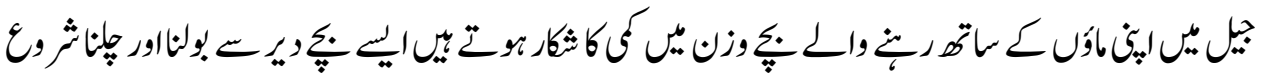

$$
\begin{aligned}
& \text { كرت }
\end{aligned}
$$

"Apart from the physical signs of prison such as stunted height, low weight and the ability to speak developing later than usual, means they start speaking at a later age than normal". ${ }^{17}$

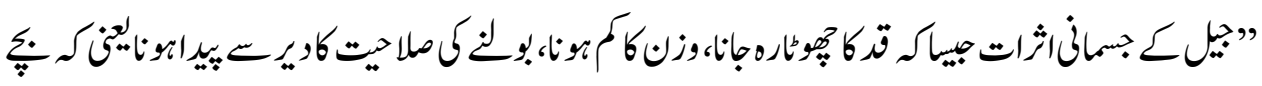

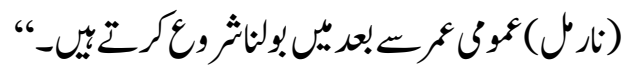

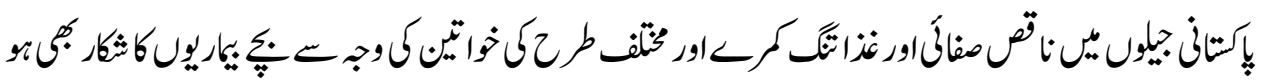

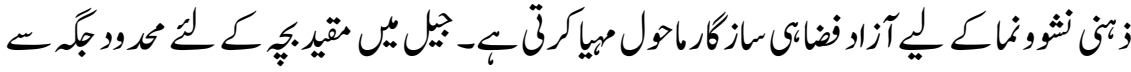

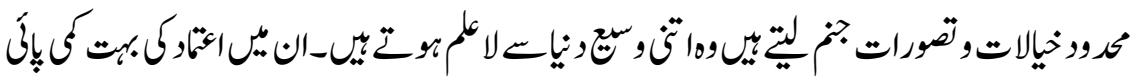

16 “Pakistan Prison Rules 1978," R: 489(i).

${ }^{17}$ Zainab Sadia Saeed, "Young, Innocent and Behind Bars," Sunday

Magazine, Dawn, May 22, 2016, https://www.dawn.com. 


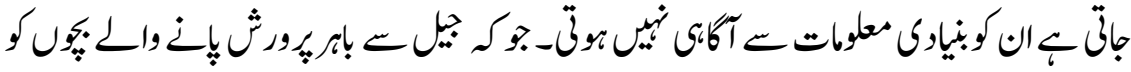

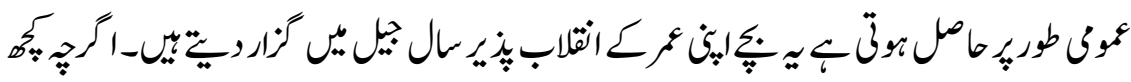

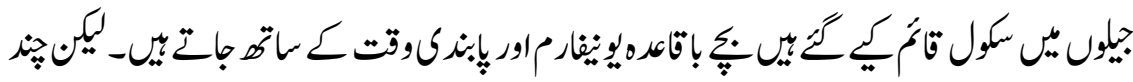

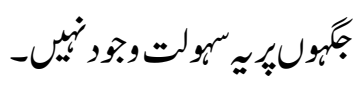

Legal Aid Office (LAO) representative Ramsha Rais says:

"They are often found to be lacking in basic knowledge "we took the kids out on a field trip to the zoo, they called every animal they saw "cat" they recognized it as a cat, because they've only ever seen cats" 18

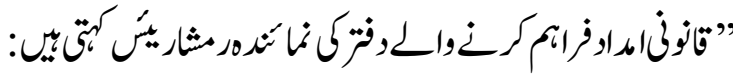

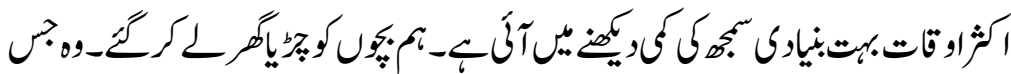

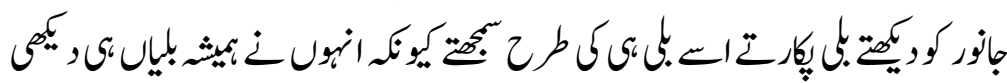

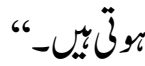

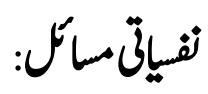

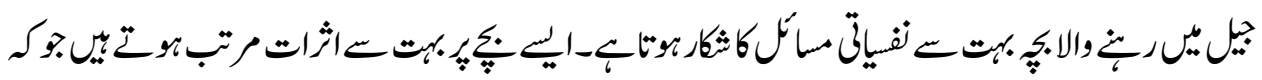

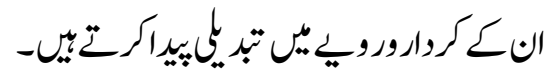

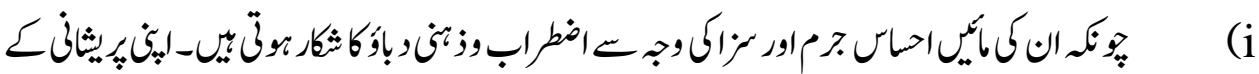

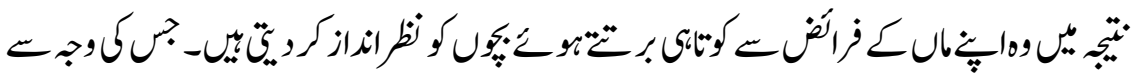

$$
\text { ني }
$$

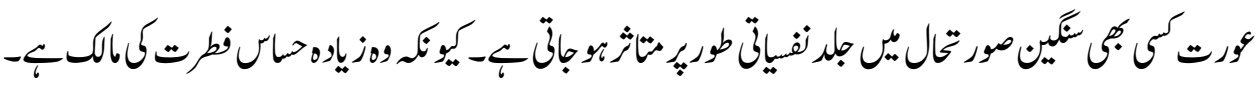

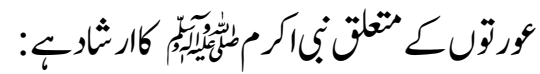

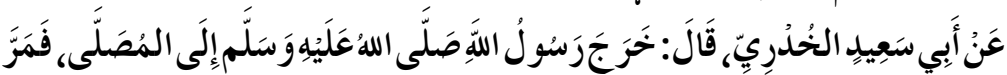

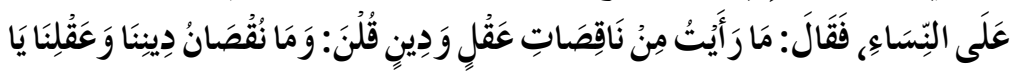

Ibid. 


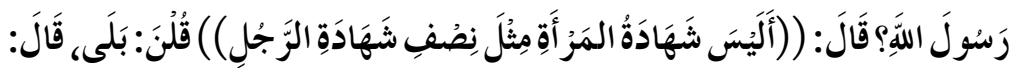

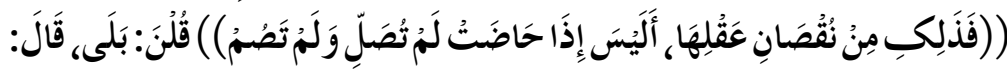

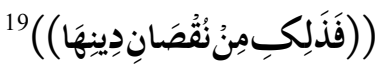

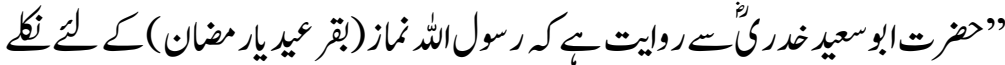

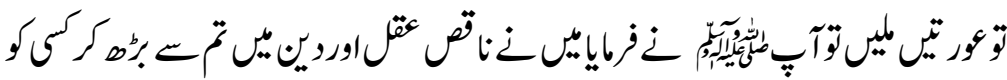

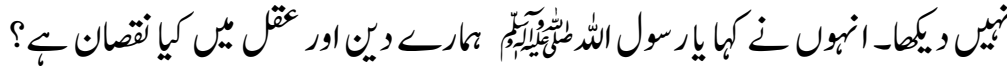

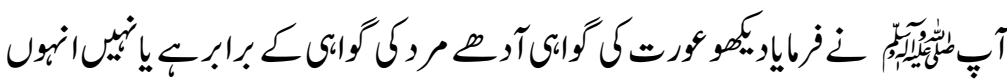

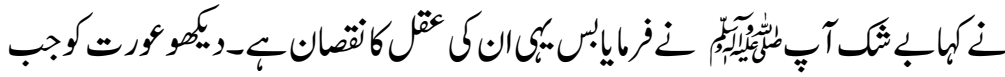

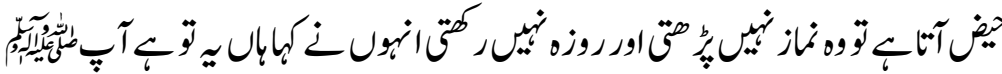

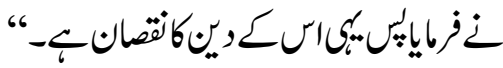

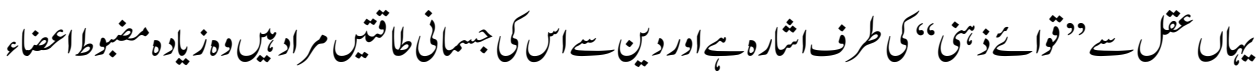

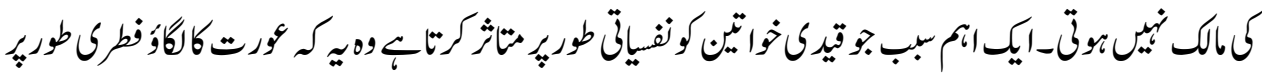

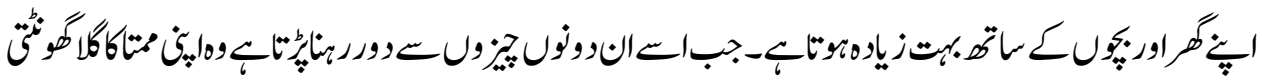

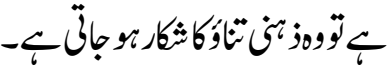

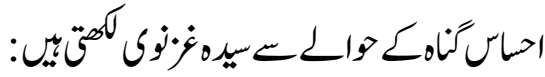

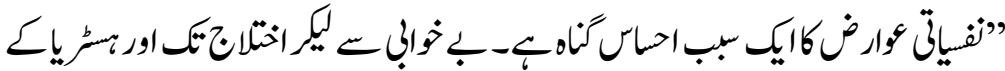

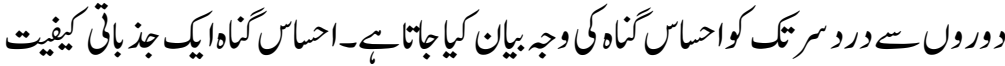

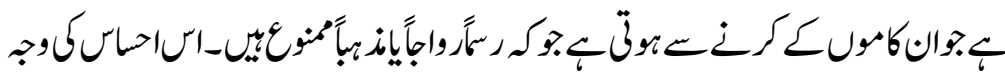

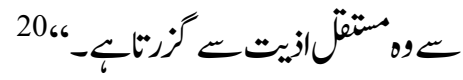

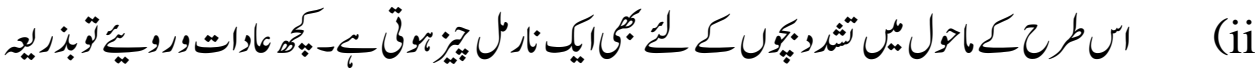

${ }^{19}$ Abū 'Abd Allāh Muhammad ibn Ismā’̄il Al-Bukhārī, Șahīh Al-Bukhārī, First (Beirut: Dar Touq-al-Najaat, n.d.), Hadith: 304.

${ }^{20}$ Syeda Sadia Ghaznavi, Nabi-e-Akram (S.A.W.W)Bator Mahir-e-Nafsiat (Lahore: Sana Publications, 1989), 35. 


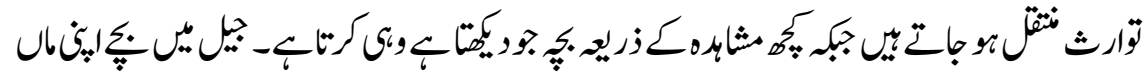

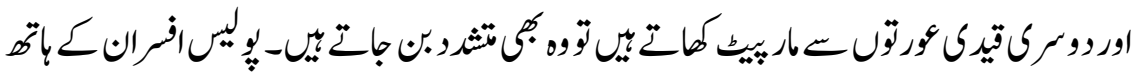

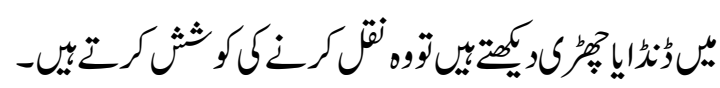

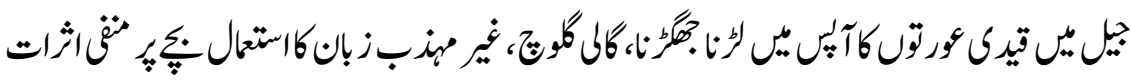

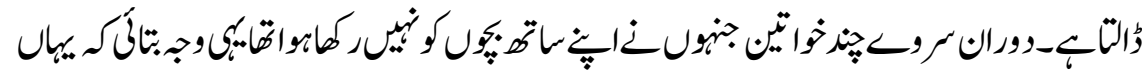

"Children are often subjected to violence by the mother and other inmates, to foul language used by inmates. All these factors damage the mental and physical growth of the child". ${ }^{21}$

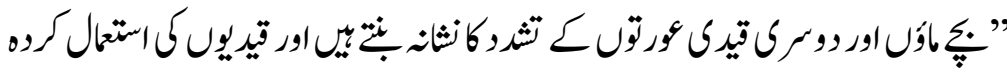

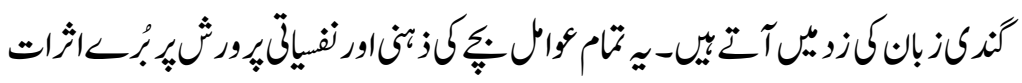

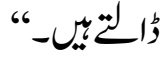

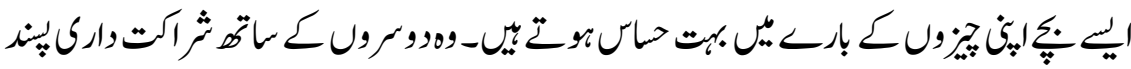

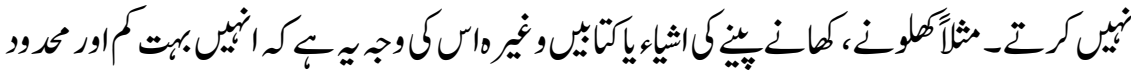

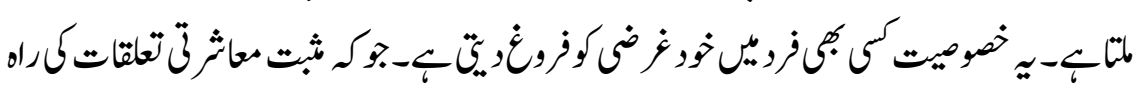

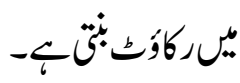

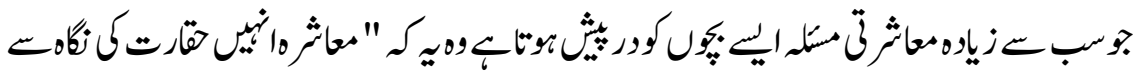

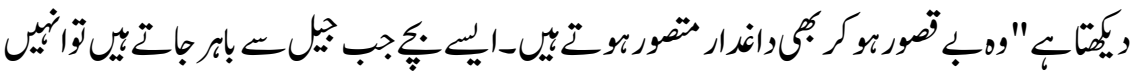

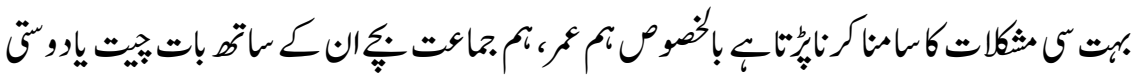

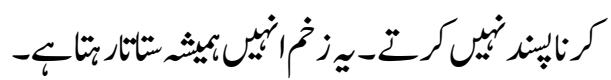

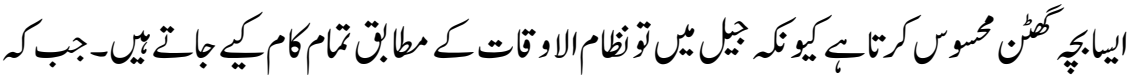

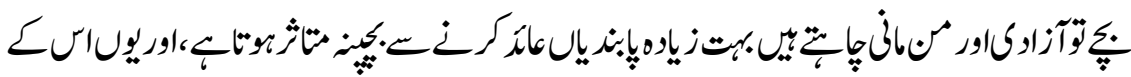

${ }^{21}$ Ibid. 
The Scholar Islamic Academic Research Journal

Vol. 7, No. 1 || January -June 2021 || P. 1-22

https://doi.org/10.29370/siarj/issue12urduar1

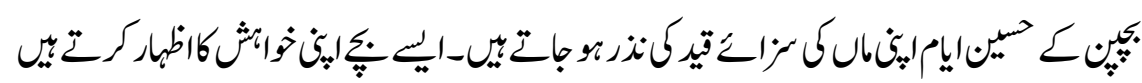
كمكران"

） ：نii

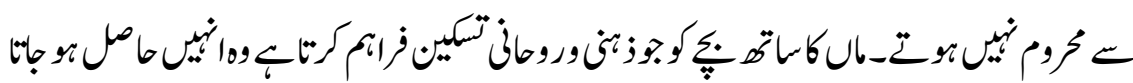

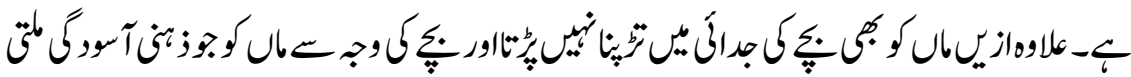

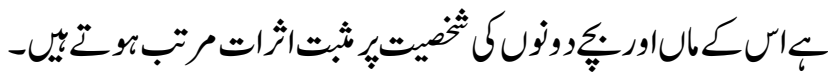

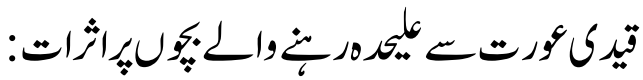

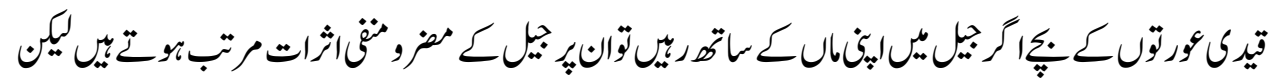

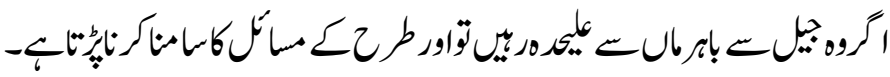

\section{(i}

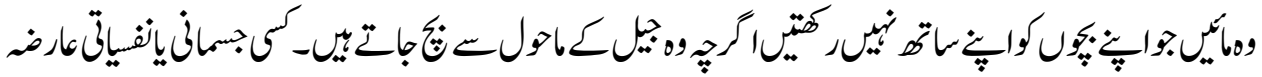

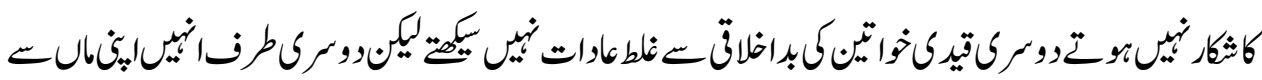

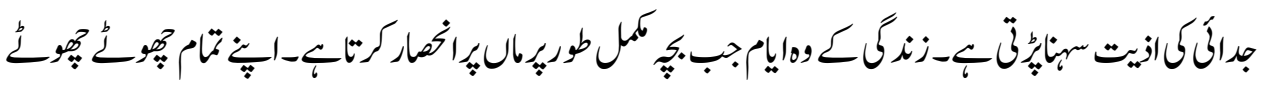

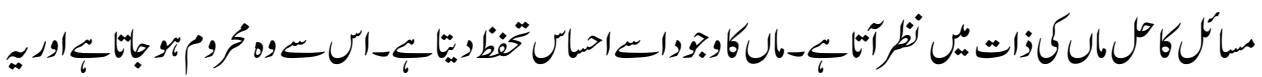

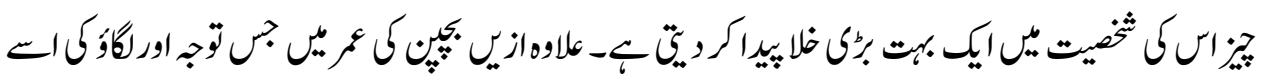

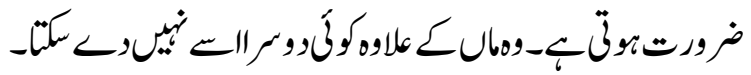

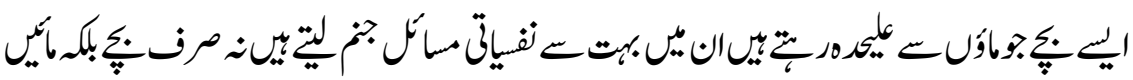

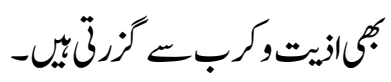

(iii

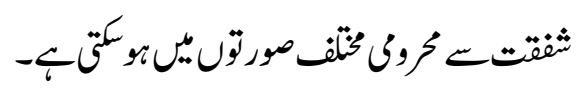

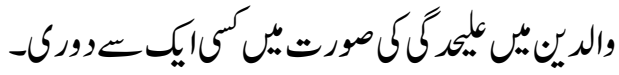

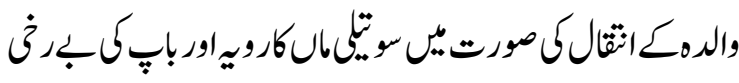

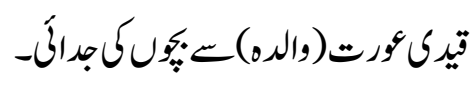




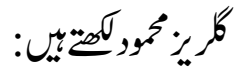

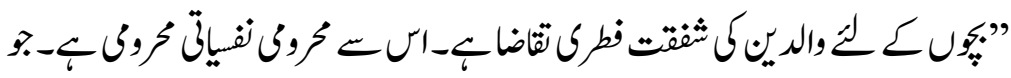

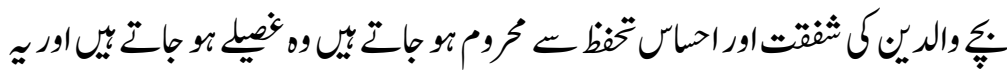

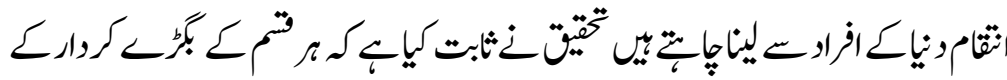

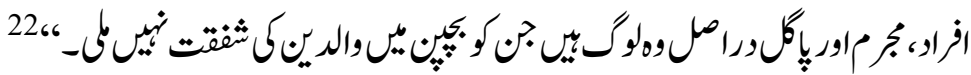

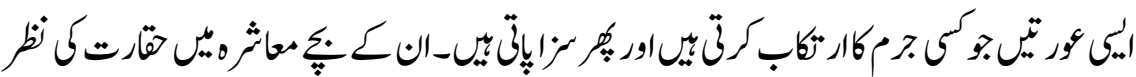

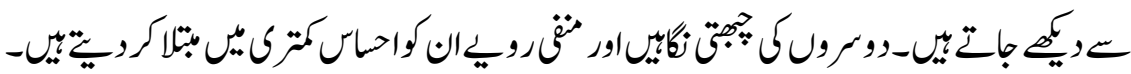

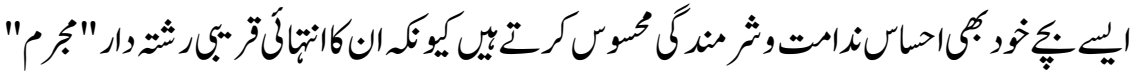

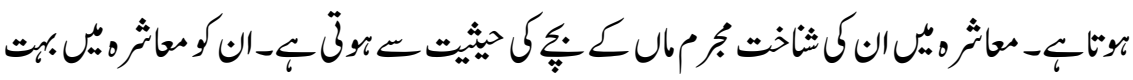

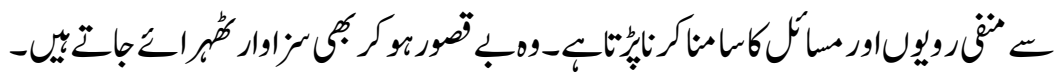

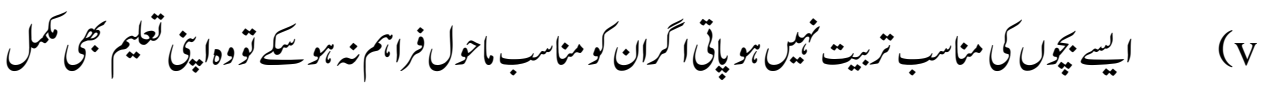

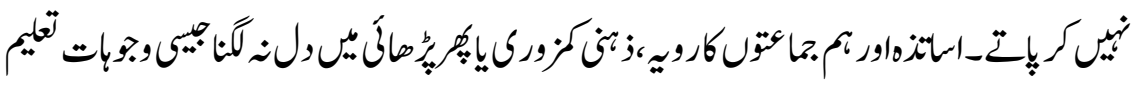

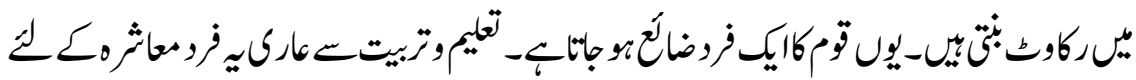

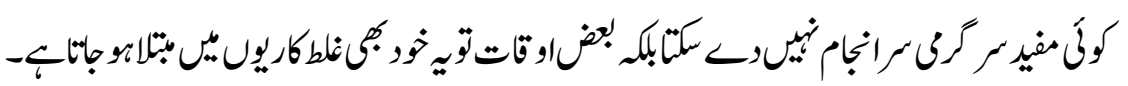

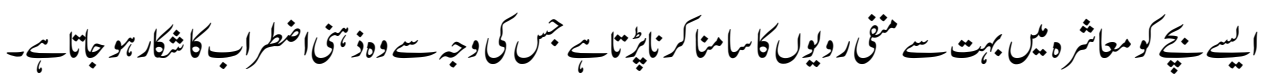

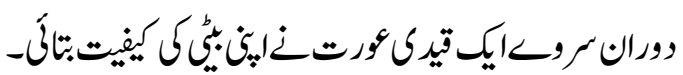

"When my daughter had to leave me and went to live with her father she couldn't continue her education; students and teachers discriminated against her and called her harsh names. She is embarrassed to even walk on the streets, just because she is the daughter of an inmate". ${ }^{23}$

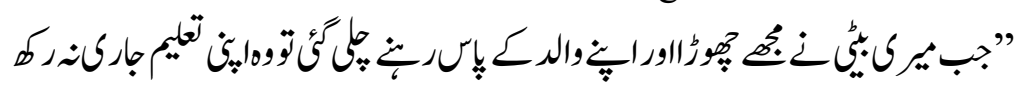

\footnotetext{
${ }^{22}$ Gulraiz Mehmood, Hamary Bachy Aur Waldain Ki Sharai Zimadarian (Lahore: Maktaba Jadeed, 2013), 216.

${ }^{23}$ Saeed, "Young, Innocent and Behind Bars."
} 
The Scholar Islamic Academic Research Journal

Vol. 7, No. 1 || January -June 2021 || P. 1-22

https://doi.org/10.29370/siarj/issue12urduar1

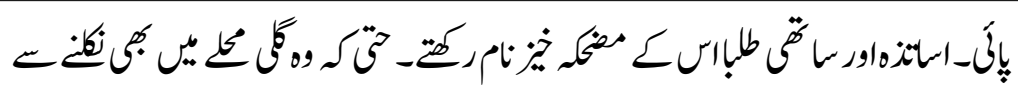

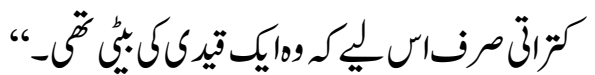

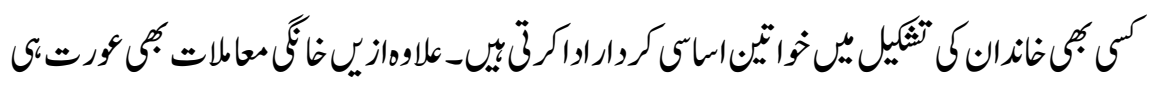

(vi

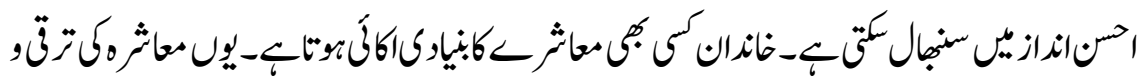

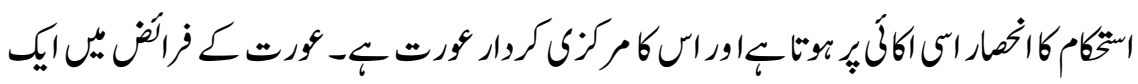

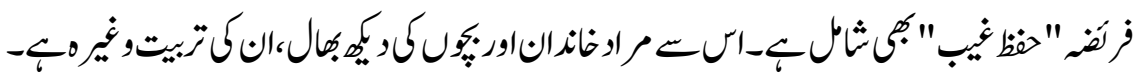

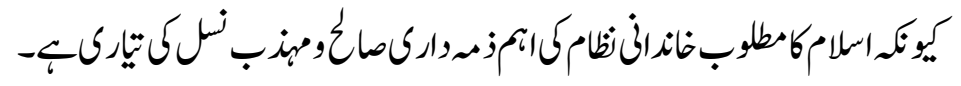

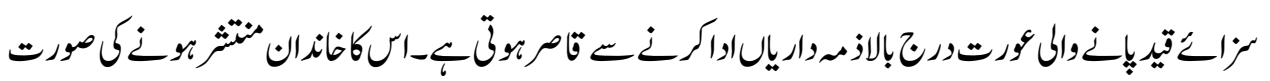

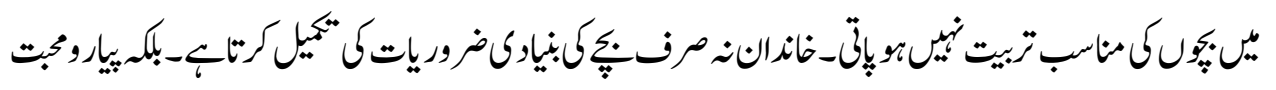

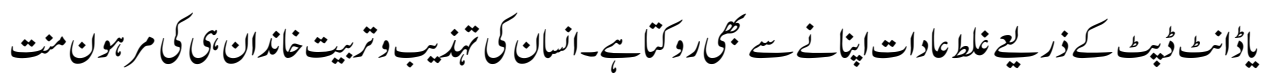

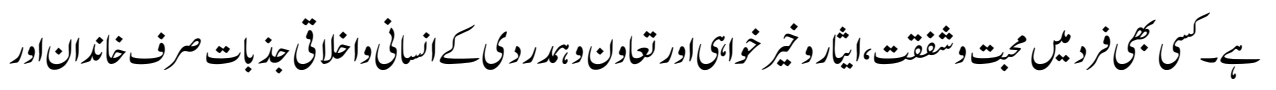

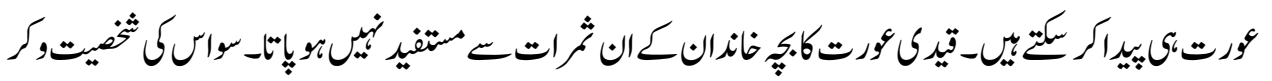

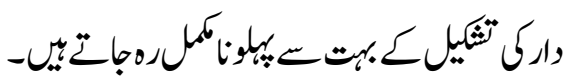

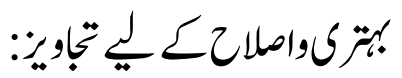

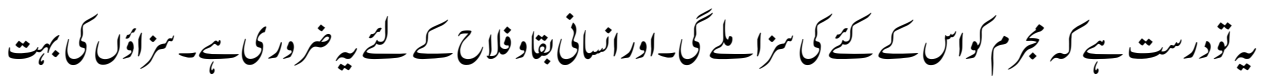

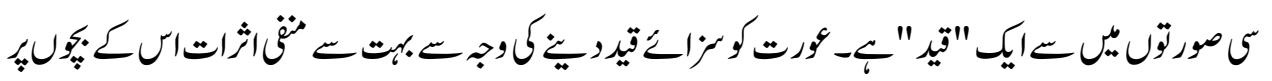

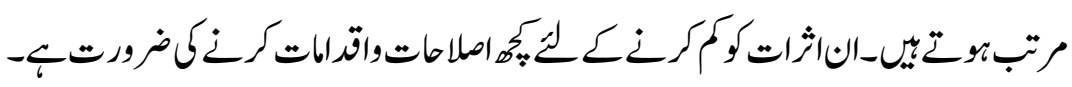

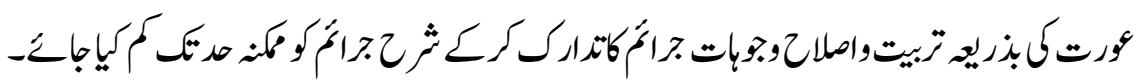

(i

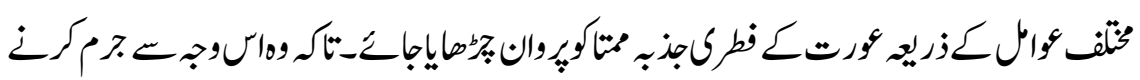

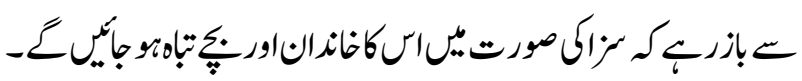

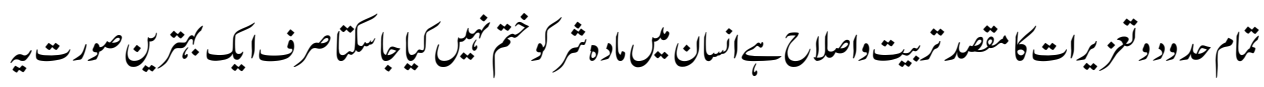

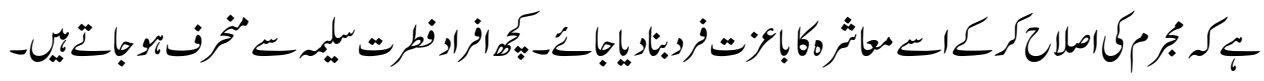

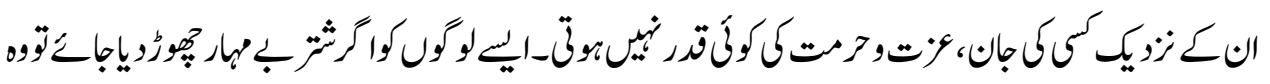

17 


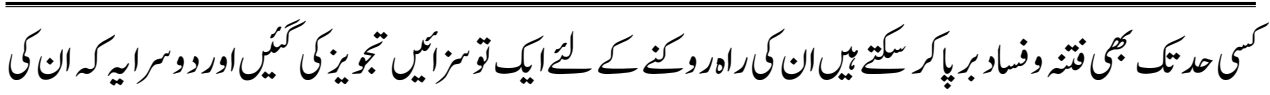

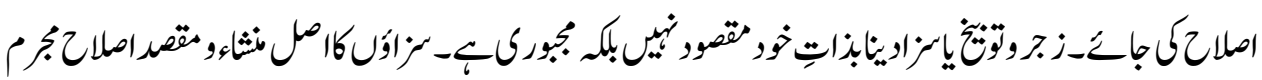

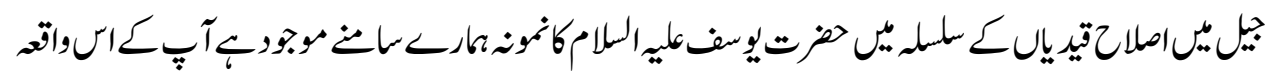

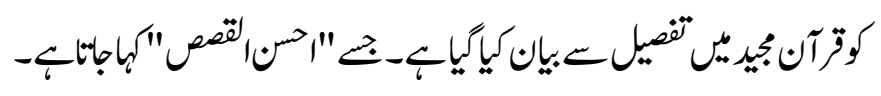

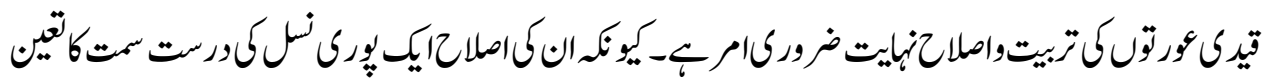

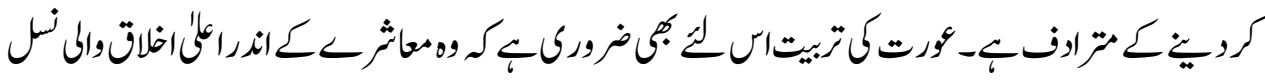

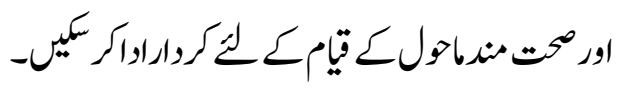

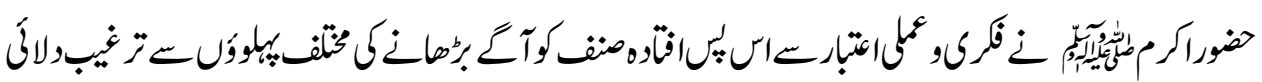

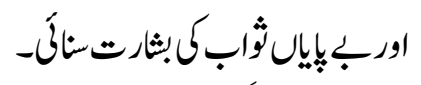

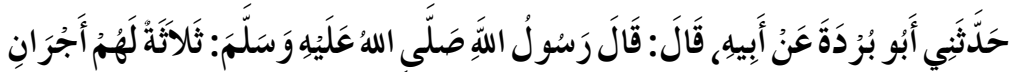

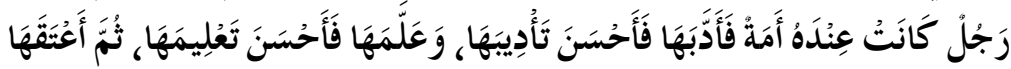

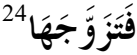

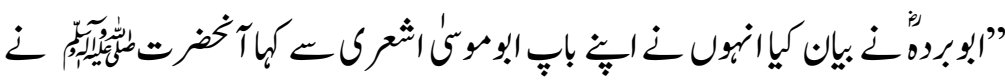

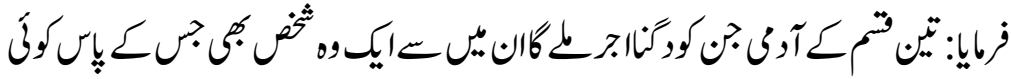

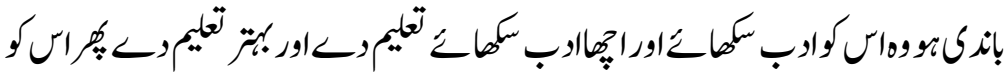

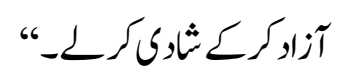

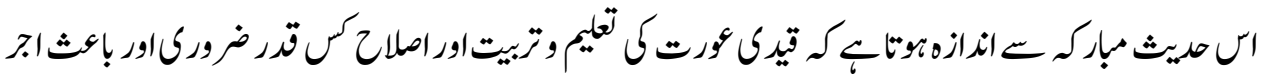

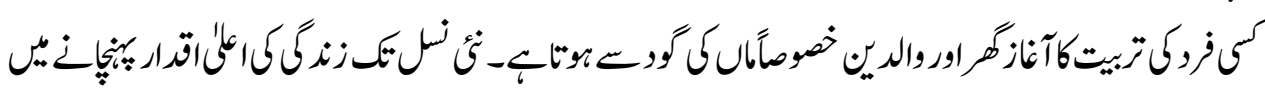

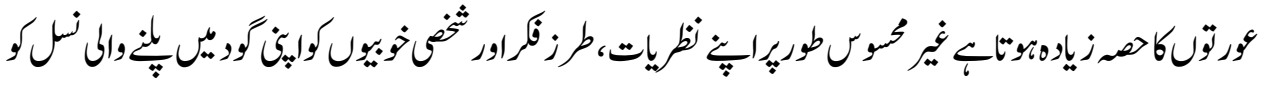

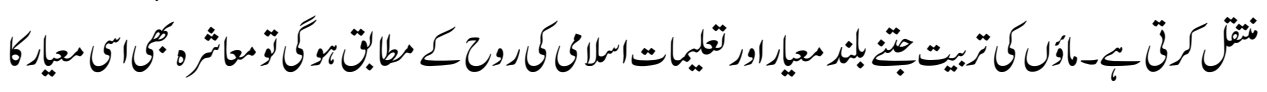

${ }^{24}$ Al-Bukhārī, Șaḥịh Al-Bukhārī, Hadith: 97. 


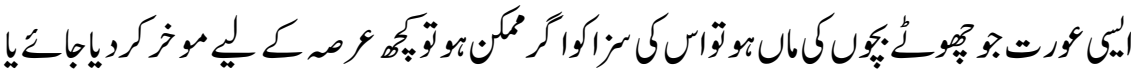

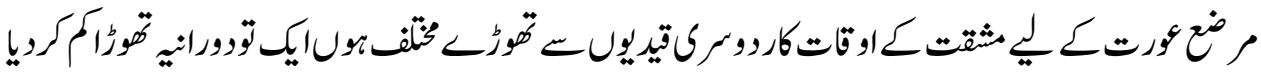

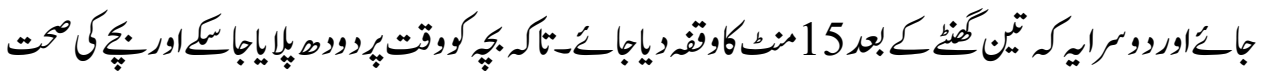

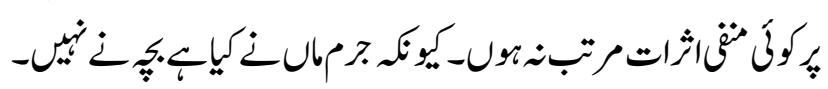

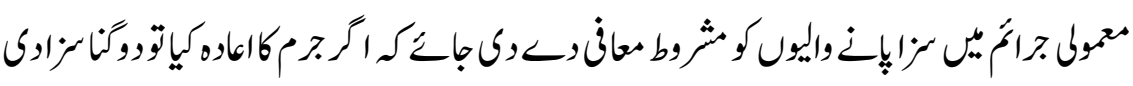

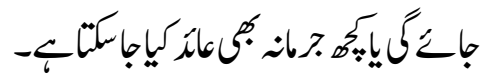

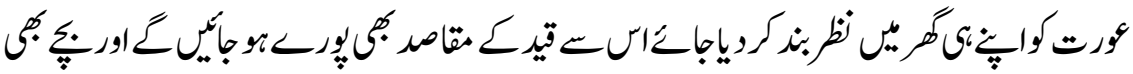

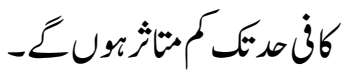
（v

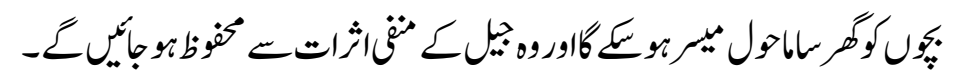

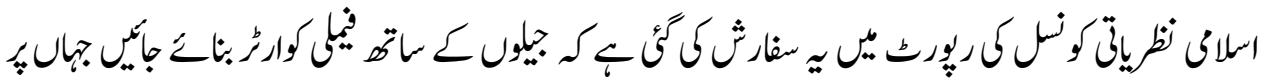

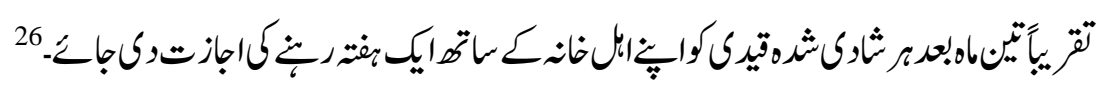

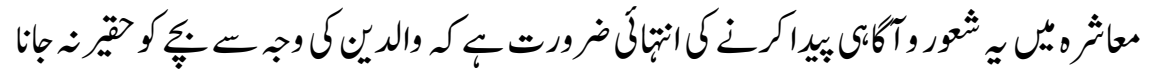
(vi

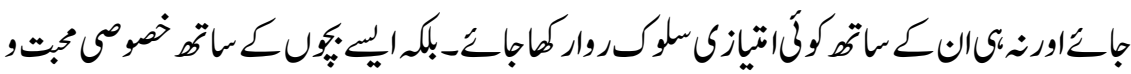

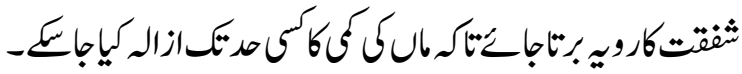

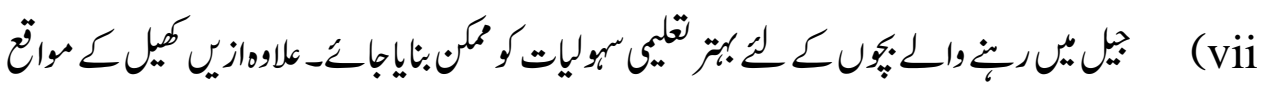

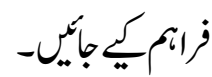

${ }^{25}$ Faiza Ehsan Siddiqui, "Islah-e-Muashrah-Mein-Khawateen-Ka-Kirdar" (Maqalah Qaumi Seerat Conference Barai Khawateen, Islamabad: Wazarat e Mazhabi Amoor wa Aqliyati Amoor, 1987).

${ }^{26}$ Sayed Afzal Haidar, "Islah Qediyan Wa Jail Khanajaat," Report wa Sifarshaat (Islamabad: Islami Nazriyati Council, 2009), 38. 


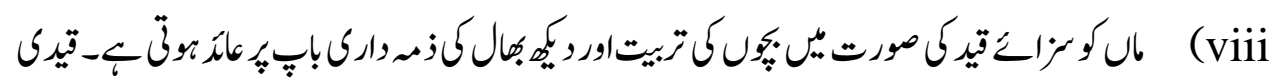

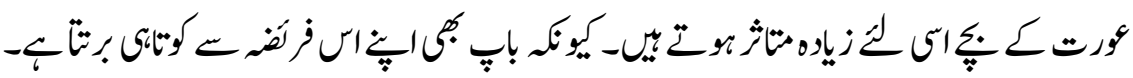

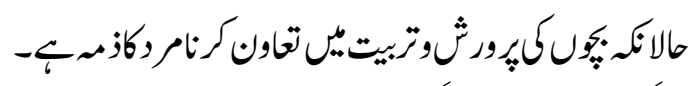

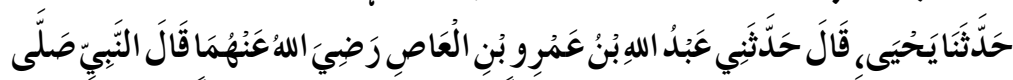

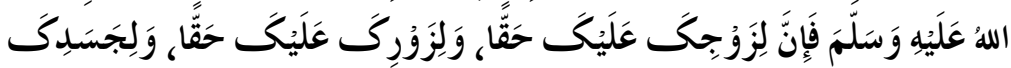

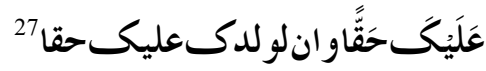

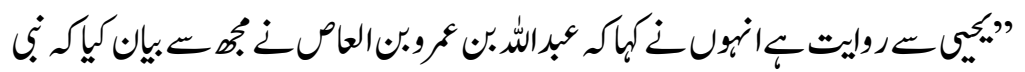

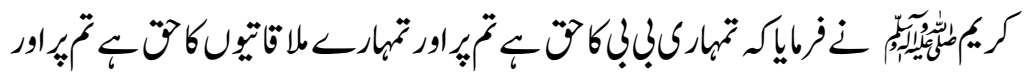

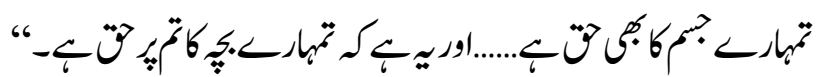

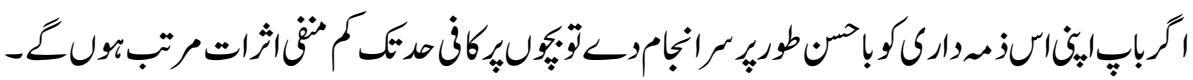

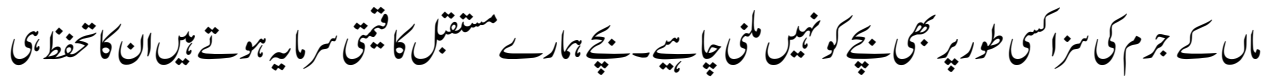

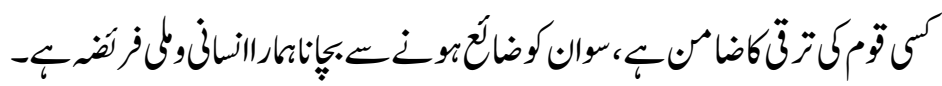

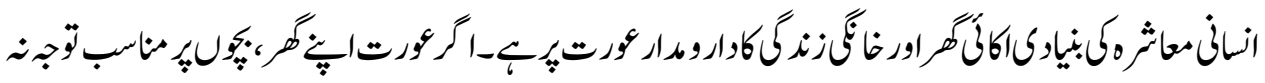

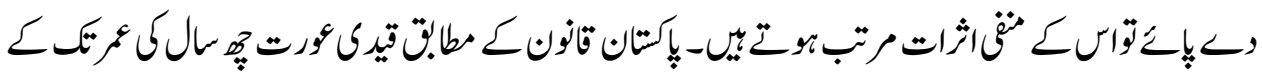

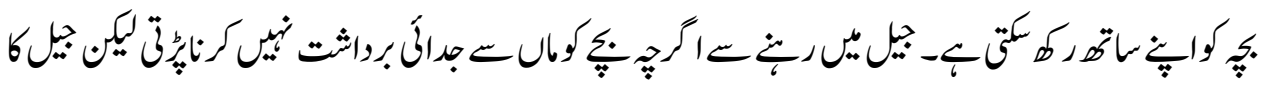

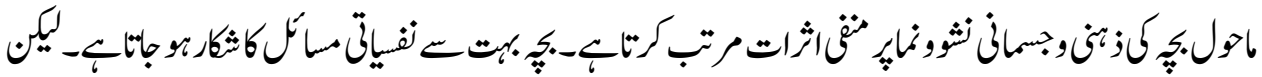

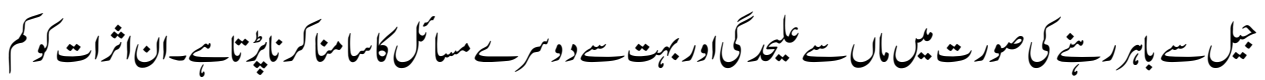

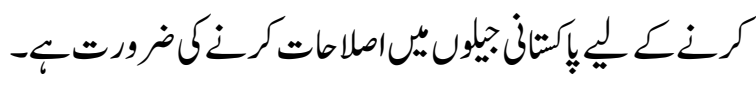

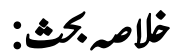

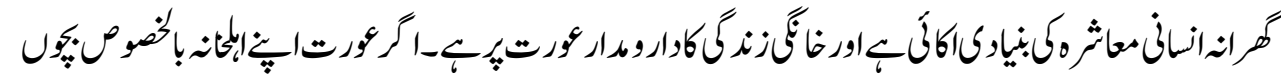

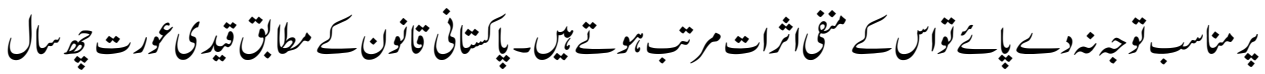

${ }^{27}$ Muslim Ibn Al-ḥajjāj Al-qushayrī Nīshāpūrī, Șaḥịh Muslim (Beirut: Dār Ihyāa al-Turāth al-Arabī, n.d.), Hadith: 2730, 2731. 
The Scholar Islamic Academic Research Journal

Vol. 7, No. 1 || January -June 2021 || P. 1-22

https://doi.org/10.29370/siarj/issue12urduar1

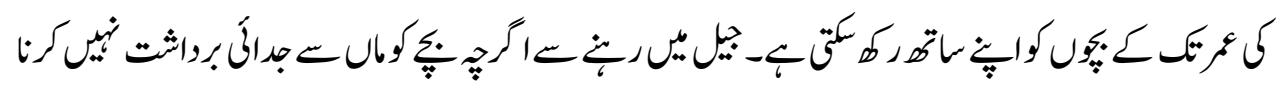

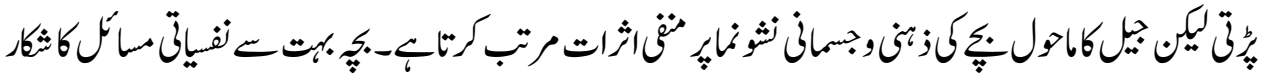

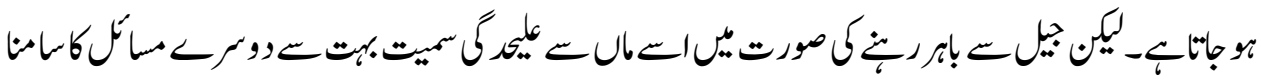

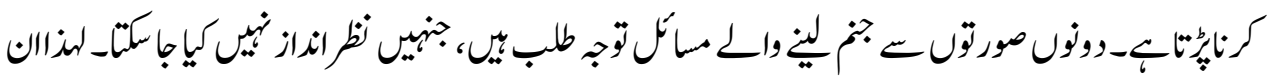

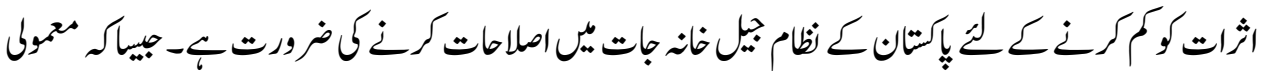

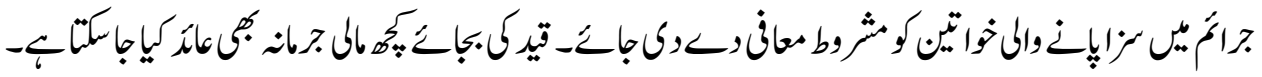

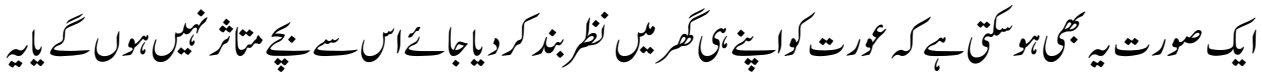

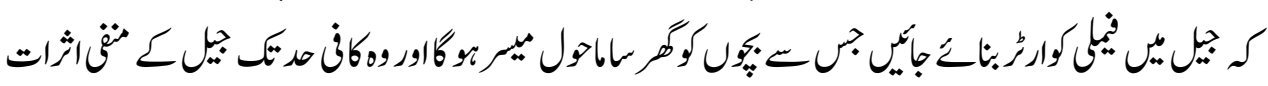

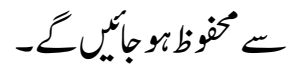

\section{(c) (P) (O)}

Attribution-NonCommercial-ShareAlike 4.0 International (CC BY-NC-SA 4.0) 